\title{
BLAST BIOLOGY
}

\section{Technical Progress Report}

By

Clayton S. White

Donald R. Richmond

September 18, 1959

Lovelace Foundation for Medical Education and Research

Albuquerque, New Mexico

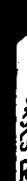

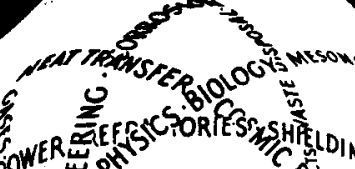
OWNRR

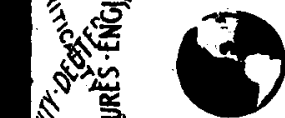

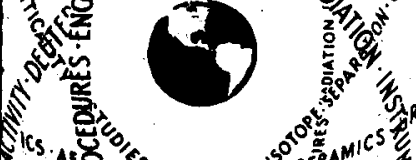

Acs At
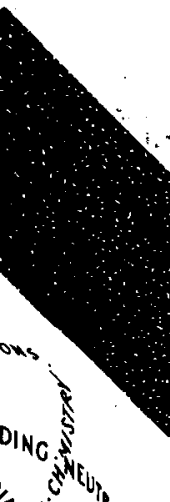


\section{DISCLAIMER}

This report was prepared as an account of work sponsored by an agency of the United States Government. Neither the United States Government nor any agency Thereof, nor any of their employees, makes any warranty, express or implied, or assumes any legal liability or responsibility for the accuracy, completeness, or usefulness of any information, apparatus, product, or process disclosed, or represents that its use would not infringe privately owned rights. Reference herein to any specific commercial product, process, or service by trade name, trademark, manufacturer, or otherwise does not necessarily constitute or imply its endorsement, recommendation, or favoring by the United States Government or any agency thereof. The views and opinions of authors expressed herein do not necessarily state or reflect those of the United States Government or any agency thereof. 


\section{DISCLAIMER}

Portions of this document may be illegible in electronic image products. Images are produced from the best available original document. 


\section{LEGAL NOTICE}

This report was prepared as an account of Government sponsored work. Neither the United States, nor the Commission, nor any person acting on behalf of the Commission:

A. Makes any warranty or representation, expressed or Implied, with respect to the accuracy, completeness, or usefulness of the information contained in this report, or that the use of any information, apparatus, method, or process disclosed in this report may not infringe privately owned rights; or

B. Assumes any llabilities with respect to the use of, or for damages resulting from the use of any information, apparatus, method, or process disclosed in this report.

As used in the above, "person acting on behalf of the Commisaton" Includes any employee or contractor of the Commission, or employee of such contractor, to the extent that such employee or contractor of the Commission, or employee of such contractor prepares, disseminates, or provides access to, any information pursuant to his employmeat or contract with the Commisston, or his employment with such contractor.

This report has been reproduced directly from the best available copy.

Printed in USA. Price $\$ 1.00$. Available from the Office of Technical Services, Department of Commerce, Washington 25, D. C.

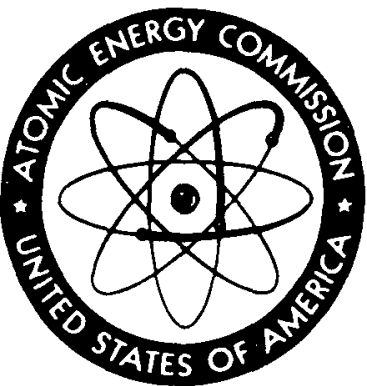




\title{
BIAAST BIOLOGY
}

\author{
Clayton S. White, M.D. \\ Director of Research \\ and \\ Donald R. Richmond, Ph.D. \\ Head, Department of \\ Comparative Environmental Biology
}

Submitted as a

Technical Progress Report

to

The Division of Biology and Medicine

United States Atomic Energy Commission

on

Contract No. AT(29-1)-1242

September 18, 1959

Note: The Division of Biology and Medicine of the United States Atomic Energy Commission has made an edited version of this manuscript available for inclusion as a chapter in Cardiopulmonary Physiology, a textbook prepared under the sponsorship of the American College of Chest Physicians, published by Grune \& Stratton, Inc., New York, N. Y. (In press, 1960)

The Lovelace Foundation for Medical Education \& Research

Albuquerque, New Mexico 
ABSTRACT

Selected information from the literature and new experimental data regarding the biologic consequences of exposure to the several environmental variations associated with actual and simulated explosive detonations were reviewed. As background, brief and elementary remarks concerning blast physics and terminology were set forth. The scope of what now comprises the field of blast biology was noted to include primary, secondary, tertiary and miscellaneous blast effects as those attributable, respectively, to variations in environmental pressure, trauma from blast-produced missiles (both. penetrating and nonpenetrating), the consequences of physical displacement of biological targets by blast-produced winds and hazards due to ground shock, dust and thermal phenomena not caused by thermal radiation per se. Primary blast effects were covered in detail noting physical-biophysical factors contributing to the observed pathophysiology. Also, a simple hydrostatic model was utilized diagrammatically in pointing out possible etiologic mechanisms. The gross biologic response to single, "fast"-rising overpressures were described as was the tolerance of mice, rats, guinea pigs and rabbits to "long"duration pressure pulses rising "rapidly" in single and double steps. Further, a few data were noted regarding biological response to "slowly" rising overpressures of "long" duration. Attention was called to the similarities under certain circumstances between thoracic trauma from nonpenetrating missiles and that noted from air blast. The association between air emboli, increase in lung weight (hemorrhage and edema) and mortality was discussed. Information relevant to the clinical symptoms and therapy of blast injury was presented and the needs for additional investigations were emphasized. The relation of blast hazards to nuclear explosions was assessed and one approach to predicting the maximal, potential casualties from blast phenomena was presented making use of arbitrary and tentative criteria. Finally, the sound sense of practicing blast, radiation and thermal prophylaxis as a means of minimizing casualties was urged as an essential step to enhance individual and national survival in the event of a nuclear war. 
ACKNOW LEDGEMENTS

The authors wish to acknowledge their indebtedness to the following employees of the Lovelace Foundation for assistance in gathering data and in preparing this report:

Dr. T. L. Chiffelle for guidance in pathology

Mr. V. C. Goldizen, Mr. V. R. Clare and Miss Faith

Sherping for technical assistance

Mr. Robert A. Smith, Mr. G. S. Bevil, and Mr. E. M.

Johnsen for preparing the illustrative material

Mrs. Isabell D. Benton for editorial and secretarial aid, and Mrs. Martina B. Smith and Mrs. Joanne Upthegrove for secretarial assistance. 
ABSTRACT . . . . . . . . . . . . • . . . 1

ACKNOW LEDGEMENTS . . . . . . . . . . . . . . 2

INTRODUCTION . . . . . . . . . . . . . . 8

BLAST PHYSICS AND TERMINOLOGY . • • • . • . . . 8

SCOPE OF BLAST BIOLOGY. . . . . . . . . . . . . . . 11

Primary Blast Effects . . . . . . . . . . . . 11

Secondary Blast Effects .............. . 11

Tertiary Blast Effects . . . . . . . . . . . . 11

Miscellaneous Blast Effects... . . . . . . . . 12

PRIMARY BIAST EFFECTS. . . . . . . . . . . . 12

Physical-Biophysical Factors . . . . . . . . . 13

Spalling Effects . . . . . . . . . . . . 13

Implosion Effects . . . . . . . . . . . . 13

Inertia Considerations . . . . . . . . . . . . 14

Relation Between Body Size and the Physical Dimensions of a Pressure Pulse . . . . . . . . . 14

Pressure Differentials. . . . . . . . . . 15

Biologic Response . . . . . . . . . . . . 25

Overpressures of "Short" Duration . . . . . . . 25

The Overpressure-Duration Relationship . . . . . 26

"Long"-duration Overpressures . . . . . . . . 27

"Fast"-rising overpressures . . . . . . . . 30

Single-step pressure rise... . . . . . . 30

Double-step pressure rise . . . . . . . 30

"Slowly"-rising overpressures . . . . . . 35

Local Thoracic Trauma . . . . . . . . . . 38

Pathophysiologic Observations . . . . . . . . 40

Conditions of exposure . . . . . . . . . 40

Causes of death . . . . . . . . . . . 41

Air emboli, hemorrhage and edema . . . . . 41

Heart. . . . . . . . . . . . . 48

Central nervous system ......... . . 51

General. . . . . . . . . . . . 51 
"Slowly"-rising overpressures. . . . . . . . . 53

Local trauma . . . . . . . . . . . . 53

Notes on Symptoms and Treatment . . . . . . . 56

Prophylaxis . . . . . . . . . . 56

Position . . . . . . . . . . . . . 57

Rest ................... . 57

Pressurization . . . . . . . . . . . 58

Analgesics, sedatives and narcotics . . . . . . 58

Oxygen therapy . . . . . . . . . . . . 59

Intravenous medications and digitilization. . . . . 60

Pneumothorax, thoracentesis and antibiotics. . . . 61

Anesthesia . . . . . . . . . . . 63

General................. 64

RELATION TO NUCLEAR EXPLOSIONS . . . . . . . . . 65

Major Hazards from Nuclear Explosions . . . . . . . . 65

Prediction of Potential Casualties from Blast . . . . . . 68

Criteria for Casualty Assessment. . . . . . . . 73

Biological . . . . . . . . . . . . . 73

Physical . . . . . . . . . . . . . 74

Casualty Potential of High Yield Nuclear Explosions. . . 75

Necessity for Casualty Prevention . . . . . . . . 79

REFERENCES . . . . . . . . . . . . . . . 82

\section{ILLUSTRATIONS}

Figure 1 Diagram of model response to very slowly rising overpressures . . . . . . . . . . . .

Figure 2 Diagram of model response to slowly rising overpressures to which "protective" response is

effective .................

Figure 3 Diagram of model response to moderately "fast"rising overpressures to which "protective" response is inadequate . . . . . . . . . .

Figure 4 Diagram of model response to "fast"-rising overpressures of "short" duration . . . . . . .

Figure 5 Diagram of model response to "fast"-rising overpressures of "long" duration. . . . . . . . 
Figure 6 Mortality variations for animals exposed against and at indicated distances from the reflecting surface of a shock tube . . . . . . . . .

Figure 7

Heart of fatally injured dog exposed in a shock tube to a reflected pressure of 40 psi enduring for 6 to $8 \mathrm{sec}$...............

Figure 8

Enlarged view of coronary vessels of a dog fatally injured by a shock tube-produced, reflected overpressure of $39 \mathrm{psi}$ enduring for 6 to $8 \mathrm{sec}$.................

Figure 9 The relation between lung weight, mortality and coronary air embolism in guinea pigs surviving and fatally injured by "fast"-rising, shock tubeproduced overpressures of 6 to $8 \mathrm{sec}$ duration.

Figure 10 Enlarged view of bruised and hemorrhagic area of the myocardium of a dog fatally injured by a "fast"-rising shock tube-produced overpressure of 40 psi (reflected) enduring for 6 to $8 \mathrm{sec}$. .

Figure 11 Ventral view of lungs of a dog non-fatally injured by a sharp-rising shock tube-produced overpres sure of 24 psi (reflected) of 6 to $8 \mathrm{sec}$ duration.

Figure 12 a \& b. Dorsal and ventral views of lungs of dog exposed non-fatally to a shock tube-produced overpressure of $10 \mathrm{sec}$ duration . . . . .

c \& d. Dorsal and ventral views of normal lungs of a dog . . . . . . . . . . . . . . .

Figure 13 a. Ventral view of lungs of a dog fatally injured in a shock tube by a 6 to $8 \mathrm{sec}$ duration, reflected overpressure of $44 \mathrm{psi}$. . . . . . . . . .

b. Dorsal view of lungs of pig fatally injured at the Nevada Test Site by nuclear-produced blast.

c. Dorsal view of lungs of a dog surviving impact of a $0.4-\mathrm{lb}$ missile travelling $103 \mathrm{ft} / \mathrm{sec}$. .

d. Dorsal view of lung of a dog fatally injured by impact of a 0.4-1b missile travelling $207 \mathrm{ft} / \mathrm{sec}$.

Figure 14 The estimated ranges for a 1 MT surface explosion corresponding to tentative criteria defining the threshold for potential blast casualties from overpressure, missiles and displacement . .

Figure 15 The estimated areas for a $1 \mathrm{MT}$ surface explosion over which potential blast casualties can be expected from overpressure, missiles and displacement . . . . . . . . . . . 
Figure 16 The estimated ranges for a $10 \mathrm{MT}$ surface explosion corresponding to tentative criteria defining the threshold for potential blast casualties from overpressure, missiles and displacement . . . . . . . . . . .

Figure 17 The estimated areas for a $10 \mathrm{MT}$ surface explosion over which potential blast casualties can be expected from overpressure, missiles and displacement . . . . . . . . . . .

TAB LES

Table 1 Approximate relationship between incident, reflected, and dynamic pressures and wind velocities calculated for sea level conditions

Table 2 Pressure-duration relationship for near 100 per cent mortality in dogs exposed to sharprising, "short"-duration high explosive blast.

Table 3 Pressure-duration relationships for the indicated mortality in mice exposed in a shock tube to sharp-rising, "short"-duration overpressures . . . . . . . . . . . .

Table 4 Mortality data for "fast"-rising, "long"duration shock tube-produced overpressures when incident and reflected pressures are applied almost simultaneously . . . . . .

Table 5 Mortality data for guinea pigs for "fast"-rising, "long"-duration shock tube-produced overpressures when the incident and reflected overpressures are applied in two steps . . . .

Table 6 The effect on dogs of "slowly"-rising overpressures of long duration. . . . . . . . . .

Table 7 Effects of nonpenetrating missiles impacted against the lateral thoracic wall of dogs... .

Table $8 \quad$ Mortality as related to the magnitude of the reflected shock front for guinea pigs exposed side-on at various distances from the end-plate of a shock tube . . . . . . . . . . .

Table 9 Association observed in blasted guinea pigs between mortality, incidence of coronary air embolism, lung weight and a rbitrarily fixed lung damage score . . . . . . . . .

Table 10 The ranges and areas for three major effects arising from typical air nuclear explosions for indicated yields . . . . . . . . . . . 
TAB LES (Continued)

;

$\bar{\nabla}$

Table 11 Approximate areas for potential blast casualties . • • • • • • • . • • • •

Page

Table 12 Population density data for a sample of U.S. Cities ................

Table 13. Potential blast casualties for a sample of eight American cities from 1 and $10 \mathrm{MT}$ nuclear explosions . . . . . . . . 


\section{INTRODUCTION}

Though the pathophysiology associated with the exposure of man and animals to blast from bombs and other explosive sources has been studied and fairly well documented over the years (1-6), a renewed and broadened interest in the subject has developed since the first atomic explosions in 1945 (7-16). At present no thorough understanding of all facets of the subject exists; but it is nonetheless true that many of the physical and biophysical factors associated with blast hazards from modern, high-yield detonations are better appreciated than in the past. Too, additional data of a quantitative nature relating biological damage to measured alterations in the environment have become available during the last decade.

To review such information is the purpose of this report. In sequence the material which follows will first touch briefly those physical alterations in the environment that follow explosions and that are primarily responsible for biological damage. Second, the current scope of blast biology will be set forth. Third, the qualitative and quantitative aspects of the hazards related to pressure variations will be dealt with in more detail, including some of the significant biophysical and pathophysiologic observations of recent vintage. Fourth, selective remarks will be directed to the symptoms and therapy of blast damage to the thoracic organs, and last, the magnitude and extent of blast problems as they are related to nuclear explosions of varying yields will be briefly indicated.

\section{BLAST PHYSICS AND TERMINOLOGY}

Whether energy is suddenly released through chemical processes as occur on detonating conventional high explosives, or created from a change in mass as happens in nuclear explosions, there emanates from the source exploded in air - a pressure pulse that travels radially through the atmos phere. The magnitude of the pressure, usually expressed in pounds per square inch (psi), measured side-on to the advancing wave is spoken of as 
the incident or local static pressure. The duration of the pressure above the ambient - the overpressure - is measured in time units that may be a few fractions or tens of milliseconds ( $\mathrm{msec}$ ) for high explosives and few tenths to tens of seconds for large nuclear explosions. The overpressures and their durations vary with explosive yield and distance from the detonation; e.g., for a given weight explosion the overpressure decreases with distance while its duration increases with increasing range.

At any given point, depending on the geometry, range, terrain and nature of the explosion, the rising phase of the pressure pulse may either be fairly slow, as might occur inside a heavy building filling with gas through doors and windows, or almost instantaneous as frequently occurs in the open. In the latter case a shock wave often comprises the leading edge of the pressure pulse, and when such is the case, a high, pressure reflection can occur when the front impinges against a solid object or a biological target. The magnitude of the reflection may be 2 - to 9 -fold the incident pressure, depending among other things on the magnitude of the latter. The first two columns of Table 1 show the approximate relationship between selected incident and reflected overpressures calculated for sea level conditions.

After a blast-produced overpressure passes a given point there follows an underpressure which is much less in magnitude and longer in duration than the overpressure. The overpressure and underpressure pulses are accompanied by winds which blow away from and toward the explosive source, respectively. The force exerted by blast winds is called the dynamic pressure and is measured as the difference between the head-on and side-on pressures. The positive winds are much the greater in magnitude and some appreciation of the relationship between wind speeds in miles per hour ( $\mathrm{mph}$ ) and dynamic pressures are shown in the last two columns of Table 1. For orientation it is well to point out that hurricane winds of $120 \mathrm{mph}$ exert a dynamic pressure of only 0.25 psi which fact emphasizes the very high winds that are associated with blast-produced overpressures.

Blast damage to structures and to biologic media are directly or indirectly caused mostly by either pressure variations, winds or both. It is 
Table 1. Approximate Relationship Between Incident, Reflected, and Dynamic Pressures and Wind Velocities Calculated for Sea Level Conditions

\begin{tabular}{cccc}
\hline \multicolumn{2}{c}{ Max overpressure in psi } & Wind velocity \\
\hline Incident & Reflected & Dynamic & $\begin{array}{c}\text { in } \\
\text { inch }\end{array}$ \\
\hline 1 & 2 & 0.02 & 40 \\
2 & 4 & 0.1 & 70 \\
5 & 11 & 0.6 & 160 \\
10 & 25 & 2 & 290 \\
20 & 60 & 8 & 470 \\
30 & 90 & 16 & 670 \\
50 & 200 & 40 & 940 \\
100 & 500 & 125 & 1500 \\
\hline
\end{tabular}

Computed from data of Shapiro (17) 
appropriate now to look to the scope of the blast problem from the biologic viewpoint.

SCOPE OF BLAST BIOLOGY

It is convenient to set forth the variety of problems related to the biological effects of blast under four arbitrarily chosen headings which will now be noted and discussed.

\section{Primary Blast Effects}

Damage to a biological target due to blast-produced variations in environmental pressure is spoken of as primary blast effects. As a general rule, pathology is most marked in the air-containing organs - the lungs, gastrointestinal tract, the ear and paranasal sinuses - and at those locations where there is the greatest variation in tissue density. Too, there may be effects at a distance which are a consequence of damage to the air-containing organs. For example, there may be malfunction of the central nervous system or failure of the heart from vascular occlusion associated with air emboli that actually enter the circulation in the lung and reach the peripheral vascular bed via the left heart.

\section{Secondary Blast Effects}

Secondary blast effects are those due to missiles energized by blast overpressure and winds and sometimes by gravity should a structure be partly destroyed by blast and subsequently fall of its own weight. Missiles may or may not penetrate a biological target and the seriousness of the hazard depends upon their composition, shape, mass and impact velocity as well as the portion of the organism lacerated or damaged at or following missile impact. Medically, such problems can be somewhat similar to the usual ballistic ones encountered in war medicine. However, there are quantitative data refer ring to low velocity debris which are of recent origin and which produce extraordinary damage to the lungs when appropriate impact with the thoracic wall occurs. These will be noted later.

Tertiary Blast Effects

Blast damage of a tertiary character may occur as a consequence of the 
physical displacement of a biologic target by blast winds. Biologically, injury may happen during the accelerative or decelerative phases of displacement. Except for violent acceleration of different portions of the body, such as from small charges of high explosive when digits or extremities may be mascerated and destroyed, violent decelerative impact comprises the major hazard. For example, it is known, from studies at the Nevada Test Site where a standing anthropometric dummy was exposed to the winds existing at 5 psi overpressure following a nuclear explosion, that a displacement of about $22 \mathrm{ft}$ occurred during which the peak accelerative load was only near $5 \mathrm{G}$. However, the peak velocity of $21 \mathrm{ft} / \mathrm{sec}$ was attained in approximately $0.5 \mathrm{sec}(18)$. Were a human to have such an experience it is unlikely that an acceleration at $5 \mathrm{G}$, transversely, falling to near $0 \mathrm{G}$ in $0.5 \mathrm{sec}$ would prove hazardous. In contrast, impact against a hard surface at $21 \mathrm{ft} / \mathrm{sec}$ (15 mph) is sufficient to fracture over 90 per cent of human skulls as revealed in a recent study (19).

\section{Miscellaneous Blast Effects}

For the sake of completeness, miscellaneous hazards related to explosive blast should be mentioned. These involve dust, ground shock, thermal effects - other than direct-line-of-site thermal radiation - from compressive and aerodynamic heating, from hot gas and dust and from blast-caused fires.

Without further noting the interplay between primary, secondary, tertiary and miscellaneous blast effects and making any attempt now to indicate the relative importance of each, the discussion will be turned to selected qualitative and quantitative data dealing mostly with the potential biological hazard from variations in environmental pressure.

\section{PRIMARY BIAST EFFECTS}

Initially, in approaching the biological effects of blast-produced overpressures, it is useful to consider the mammal, including man, as a simple model consisting of a body of fluid confined within the elastic skin, but complicated by the inclusion of material of different densities varying from firm bone to the spongy, air-containing lung. There exist certain physical-biophysical relationships that are of importance in understanding some of the phenomena which may occur and cause blast pathology. 


\section{Physical-Biophysical Factors}

\section{Spalling Effects}

When a shock or pressure front travelling through one media attempts to pass an interface with another media of less density, there occurs at the interface a negative reflection which produces local tension in the first media. As a result, the surface of the heavier media fragments or "spalls". Similar events can involve "spalling" and dust formation inside closed structures exposed to blast $(20,21)$ and are also noted when an underwater blast wave reaches the surface where negative reflection occurs and water particles are thrown into the less dense air, causing the "spray dome", a whitish mound of broken water well known in underwater demolition work (22).

Schardin (5) has pointed out that such phenomena may occur at the fluidair interfaces of the delicate pulmonary alveoli and result in fragmentation, edema and hemorrhage, providing a pressure pulse of sufficient magnitude emanated inward from the body surface energized by a sharp application of force or pressure. There can be little doubt but that "spalling" effects deserve careful biophysical consideration.

Implosion Effects

Likewise of potential importance in the etiology of blast damage to the lung are implosion effects, a term that Schardin (5) uses to cover phenomena which are seen when an explosive-produced shock wave travelling in relatively incompressible water passes over small air bubbles. The latter, being compressible, undergo a sharp decrease in volume with the development of very high, local pressures. In fact, each bubble so "imploded" becomes the source of a "new" detonation and multiple shock waves emanate radially from the pulsating pressure in the gaseous phase. It is quite possible that damage to the air-containing portions of the lung can occur from implosion when an organism is exposed to blast overpressures, for Clemedson (23) has shown by direct means that shock fronts exist in and propagate through body tissues after the surface of an animal is struck by an explosive-produced pressure pulse travelling in air to reach the biologic target. The consequences of such phenomena taking place near the alveolar regions of the lung are not known with certainty, 
but it is likely that considerable pathology does occur both to the thin alveolar walls and the more fragile vessels of the pulmonary vascular bed.

\section{Inertia Considerations}

Yet another effect of a shock front reflecting from the surface of a biological target and penetrating inward is the transfer of momentum to different portions of the organism. At the surface, for example, equal momentum might be imparted to two equal volumes of tissue in an amount related to the magnitude of the reflected pressure, but the resulting rate of movement of each volume would depend upon their respective masses; e.g., the velocity of the lighter mass would develop more rapidly and rise to a higher value than would be the case for the heavier one. As a result of this inertia difference, local stresses and shearing forces would develop. Such considerations, for example, offer a reasonable explanation for the hemorrhagic areas often localized linearly along and near the junction of the intercostal tissues and the ribs as commonly seen and described by those familiar with blast-produced pathology.

Relation Between Body Size and the Physical Dimensions of a Fressure Pulse

The fact that explosive-produced overpressures vary in duration has been alluded to previously. It is appropriate here to call attention to a rather obvious reason why the time an overpressure lasts might well be important biologically. Consider for the moment two overpressures of 1 and $20 \mathrm{msec}$ duration and assume the pulses were travelling in air over a flat surface at a velocity of $1000 \mathrm{ft} / \mathrm{sec}$ - this is near sonic velocity $\left(1120 \mathrm{ft} / \mathrm{sec}\right.$ at $\left.60^{\circ} \mathrm{F}\right)$. The physical length of the overpressure pulse measured along its direction of travel would be approximately 1 foot for the $1 \mathrm{msec}$ pulse and $20 \mathrm{ft}$ for the $20 \mathrm{msec}$ pulse. In terms of a biologic target the size of a large dog or a man, such a difference could be important because in case of the 1 foot pulse ( $1 \mathrm{msec}$ ) only a small portion of the target could be "pressurized" at any given time, leaving the transmission of the reflected pressure into the animal or man and the movements initiated by the transfer of momentum to be the primary sources of internal damage.

In addition to these factors, another would come into play for the 20 $\mathrm{ft}(20 \mathrm{msec})$ pulse; namely, the target would be engulfed suddenly in a region 
of high pressure and be "squeezed", vice-like, from all sides. Since the gas contained "in" the fluid of the soft tissues is compressible, the body wall would move inward with time resulting in a decrease of the internal gaseous volume and also the volume of the entire animal. Because most of the gas, as such, in the body exists in the elastic but fragile lung, one would expect the response of the thorax and diaphragm (and abdominal wall) to be maximal for "fast"rising overpressures of "long" duration with damage to the organs in the chest determining one of the important, critical biophysical hazards.

This possibility will be discussed later, but let it be clear here that the relation between animal size and the physical, linear dimensions of the overpressure should be regarded as significant. As a consequence, the reader should be alert for data that might define quantitative relations between the response of large and small animals to pressure pulses of various durations.

\section{Pressure Differentials}

Before turning to the response of various species of animals to short and long duration overpressures rising to a maximum in different times, it is instructive to employ simple models to aid visualizing certain qualitative relationships between environmental pressures external to the animals and those that might be expected internally in the gaseous and fluid phases of the lung at the alveolar level.

Consider Figure 1 which diagrammatically represents the trunk of an animal with the thorax above and the abdomen below. The trachea is shown, with a constriction representing the bronchiola $r$ resistance to air flow, leading to a "box" representing the gaseous phase of the lung. Protruding into the gaseous phase, another "box" is shown representing the fluid phase of the thorax, including the vascular components, and the latter communicates with the vascular elements below the diaphragm also shown as a "box" in the abdominal region.

Now, imagine that the environmental pressure, $\mathrm{P}_{\mathrm{e}}$, is caused to rise. There exists at least four events with different and unknown time constants, each of which will influence the development of and interrelations between significant pressure differentials within the lung and across the chest wall; e.g., 


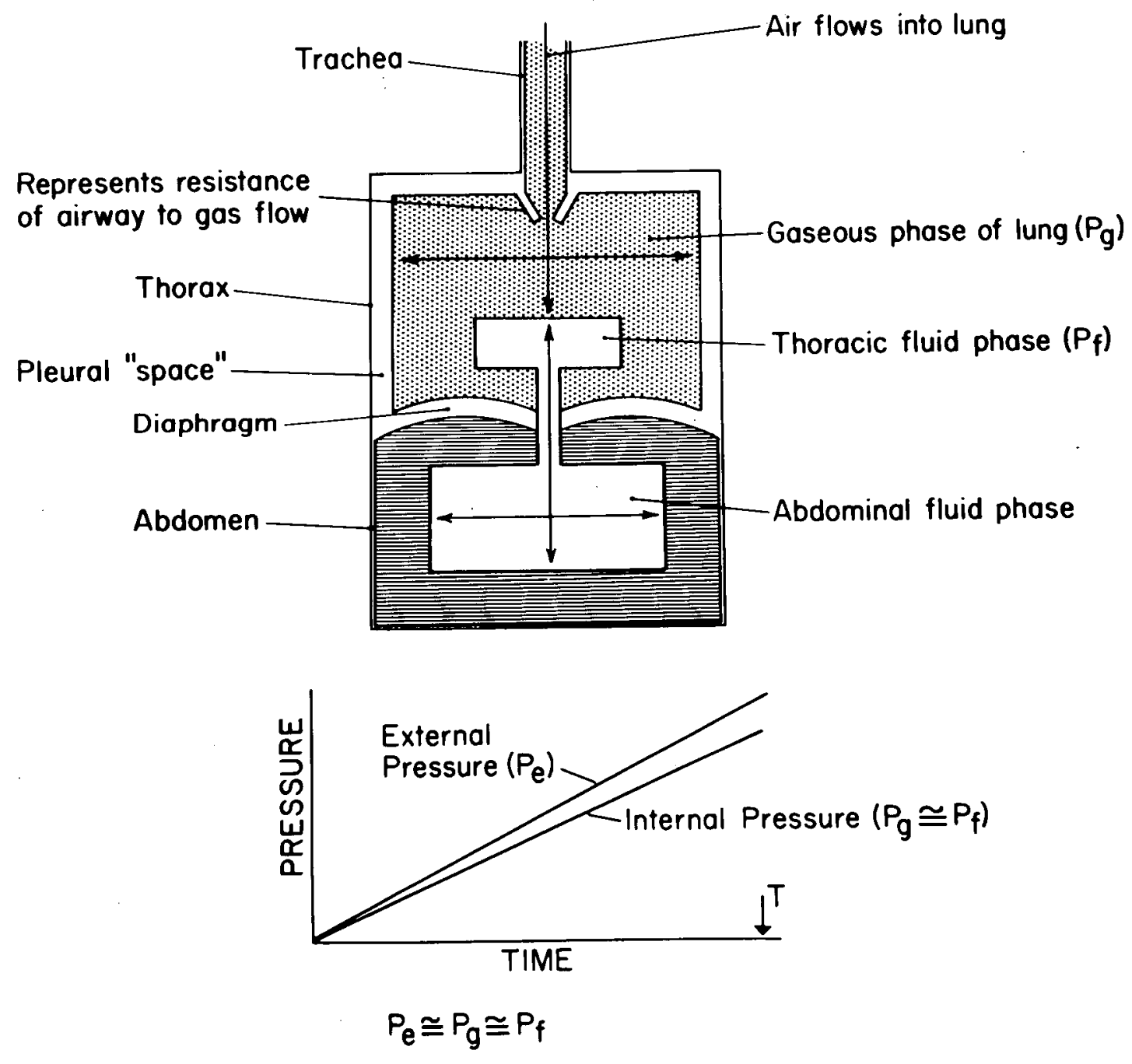

Figure 1. Diagram of model response to very slowly rising overpressures. See text for discussion. 
between the several possible combinations of the external pressure, $P_{e}$, the pressure of the alveolar gases, $\mathrm{P}_{\mathrm{g}}$, and the pressure of the fluid phase of the lung, $P_{f}$. These are: (a) air may flow through the trachea into and along the respiratory tree and thus raise the gaseous pressure in the alveoli, (b) the chest and abdominal walls may move inward, which with the consequent rise of each dome of the diaphragm, will decrease the gaseous volume in the thorax and hence raise the pressure in the gaseous phase of the lung, (c) fluid may be driven into the chest mostly from the abdomen and great veins which factor will tend also to decrease the volume of the gaseous phase of the thorax, and (d) shock or pressure pulses in the fluid phase of the body may emanate inward from the traumatized surface of the organism.

Keeping these in mind, let the reader now redirect attention to Figure 1 and visualize a quite slow rise in the pressure environment shown by $\mathrm{P}_{\mathrm{e}}$ on the pressure-time curve at the bottom of Figure 1. One can believe that there exists a rate of pressure rise, providing the airways were open and even if an animal were not breathing, which would allow time for air to flow into the thorax at a rate sufficient to keep the alveolar pressure near that in the environment as shown by the curve, $\mathrm{P}_{\mathrm{g}} \cdot$ This would also prevent any significant migration of fluid into the thorax, but the re could occur a "Ioading" of the blood passing through the thorax with respiratory gases particularly the "fast" moving carbon dioxide - as long as the pressure in the environment and in the alveoli were elevated. Such a situation may represent no hazard to the animal if the pressure elevation is not too high nor too prolonged, but might well give difficulty subsequently, as will be noted later, depending on the falling phase of the external pressure. At least during the rising phase, the pressures inside the animal would be about equal to those outside $\left(P_{e} \cong P_{g} \cong P_{f}\right)$.

A second set of circumstances involving a faster rate of rise in the environmental pressure may be visualized at a rate that outstrips the pressure compensation possible by gas flow through the respiratory tree into the alveoli, which in case of rapid air flow, offers quite high resistance. In such an instance the internal pressure will be lower than the external pressure and the thoracic volume would decrease mostly because of inward movement of the 
perimeters of the thorax, but some because fluid would also flow into the chest. These factors, plus perhaps slight air flow into the chest, would combine to equalize the internal and external pressures if the rise in environmental pressure were not too high. Figure 2 depicts such a situation and the pressuretime curves in the lower portion show the pressure differentials between the environmental and alveolar pressures that were active in driving the thoracic borders inward. The magnitude and rate of rise of the environmental pressure were assumed to be such that the internal and external pressures were equalized at time, $T$, without significant damage occurring to the animal.

In Figure 3 a similar situation is represented except that the environmental pressure was imagined to rise more rapidly and to such a high level that pressure compensation by a decrease in thoracic volume could not occur by time, $T$. With regard to the latter there is an elastic limit approached by the thoracic wall and diaphragm when the gaseous volume of the lung has decreased to near the residual volume. If the high external overpressure continued, pain would occur and blood would flow into the lung seeking to reduce further the compressible, air-volume in the chest. A consequence might well be rupture of blood vessels and massive lung hemorrhage somewhat analogous to the "squeeze" syndrome in divers described so aptly by Behnke (24). Such a contingency is depicted in Figure 3 which also shows an existing pressure differential after time, $T$, at which instant it was assumed the decrease in chest volume, due mostly to movement of the chest walls and diaphragm, was complete. Besides a decrease in chest volume and fluid flow into the gaseous portions of the lung, the only other mechanism for relieving the hazardous pressure differentials described is the flow of air into the alveoli through the pulmonary airways which may be compromised early by closure of the glottis and later by deformity of the trachea, bronchial and bronchiolar structures. Subsequently, air flow into the airways will eventually equalize the internal and external pressure differentials.

For emphasis, attention is called to the possible significance of the residual volume. It so happens, in man and in the dog at least, that the residual volume is on the average about $1 / 2$ the lung volume during normal breathing. This means that an effective overpressure of about 1 atmosphere 
8

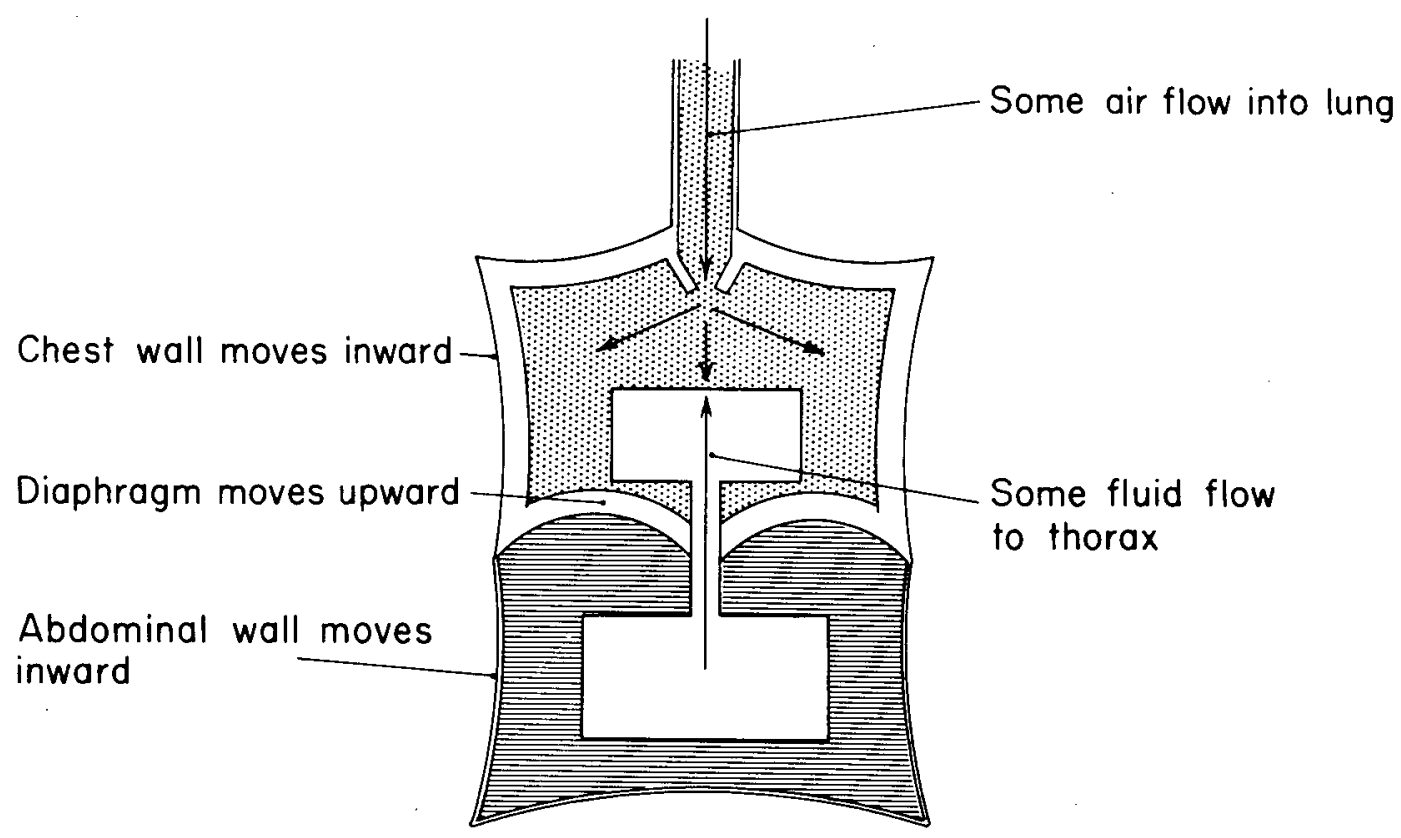

-

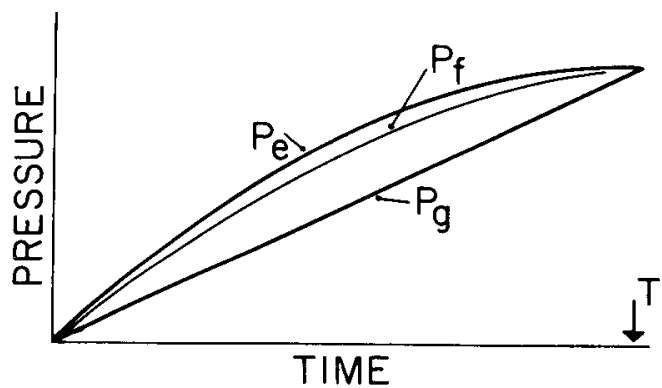

$P_{e} \cong P_{g}=P_{f}$ at time $T$
$P_{e} \cong P_{f}>P_{g}$ before time $T$

Figure 2. Diagram of model response to slowly rising overpressures to which "protective" response is effective. See text for discussion.

$\overline{-}$ 


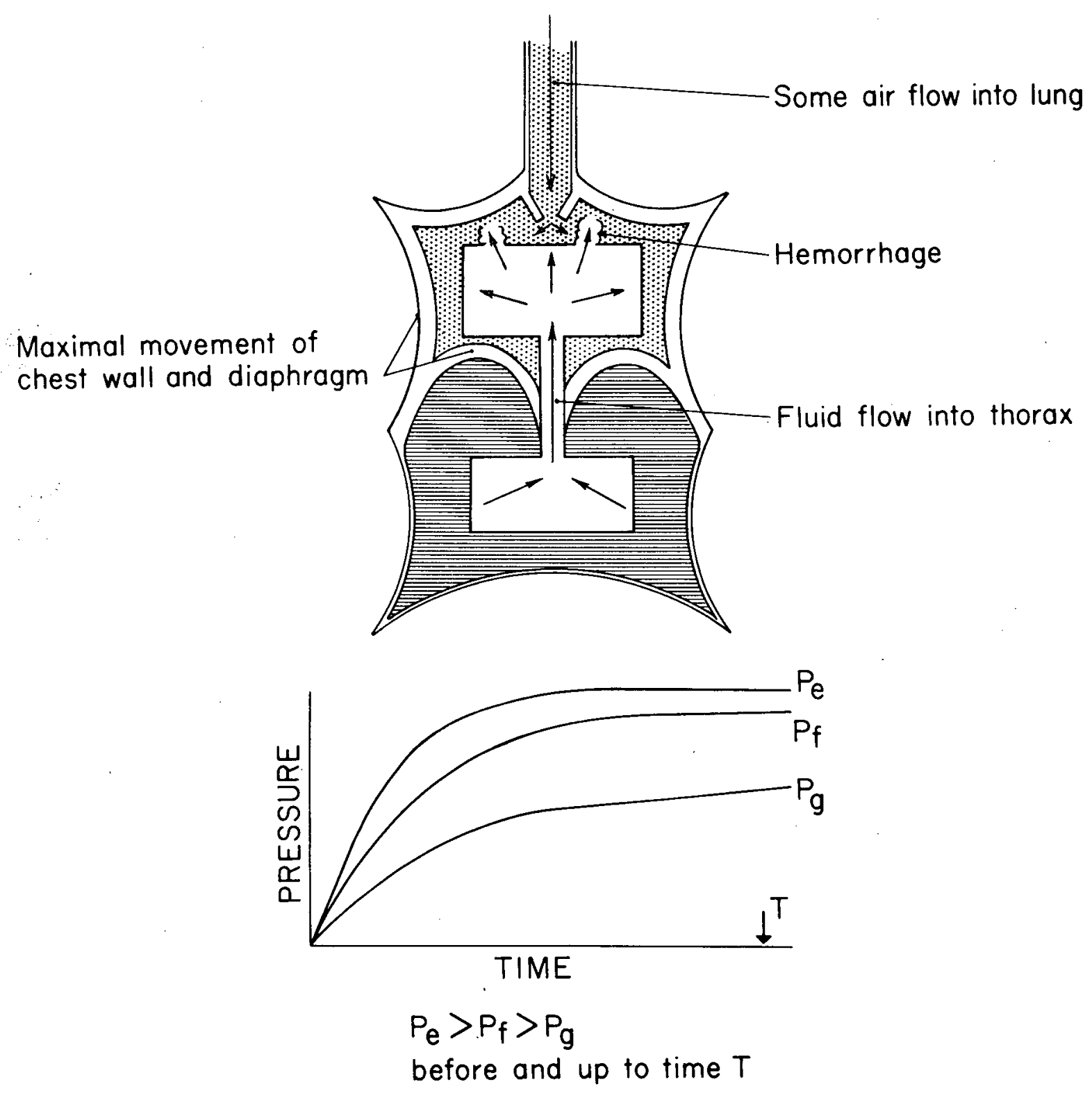

Figure 3. Diagram of model response to moderately "fast"rising overpressures to which "protective" response is inadequate. See text for discussion. 
at sea level - or more generally double the ambient absolute pressure would, if applied quickly enough to avoid much air flow into the lung, reduce the lung volume to the residual volume. Crudely, this points to an overpressure at sea level of 15 psi developing "fairly quickly" as a threshold for thoracic pathology from the "squeeze" mechanism just described, providing the animal started with a lung volume associated with normal breathing.

It is now appropriate to consider a yet more dynamic loading of the "animal" model under consideration by assuming an almost instantaneous rise of environmental overpressure of quite "short" duration, such as depicted by the top pressure-time curve in Figure 4. Under such circumstarces there probably would be little if any air flow into the chest and hardly time for any immediate inward movement of the perimeters of the thorax as a result of momentum transmitted to the body walls nor for mas flow of excess fluid into the thorax through the vascular system. However, the rapid pressure load - incident plus reflected pressure - applied to the surface of the animal can result in pressure pulses or shock waves in the fluid phase of the body. The waves move inward with the velocity of sound in water - about $5,000 \mathrm{ft} / \mathrm{sec}$ - and reach the air-fluid interfaces in the lung before an airborne pulse - travelling sonically at about $1,100 \mathrm{ft} / \mathrm{sec}$ - can traverse the respiratory tree and counter the fluid pressure by air pressure at the airfluid junction. As a consequence, a high pressure differential develops very quickly between the fluid pressure, $P_{f}$, and the alveolar gas pressure, $P_{g}$, which, if of sufficient magnitude, may rupture the membranes separating fluid and gas with subsequent hemorrhage if blood vessels were involved. Also, spalling and implosion effects may occur to add to the damage to the lace-like alveoli. Should a pathway be opened between the gas in the alveoli or bronchi and the vessels leading to the left heart, subsequent respiratory efforts by the animal could result in air being "pumped" into the circulation. The biologic consequences of such events will depend on the amount of air involved, where it goes - which is somewhat related to chance and to the position of the animal - and the effective "sealing" of such gas-blood avenues by vasoconstriction, local hemorrhage, blood clotting and edema. At least this can be said to represent a very hazardous situation which is largely dependent upon the magnitude of the overpressure and its duration. Actually 


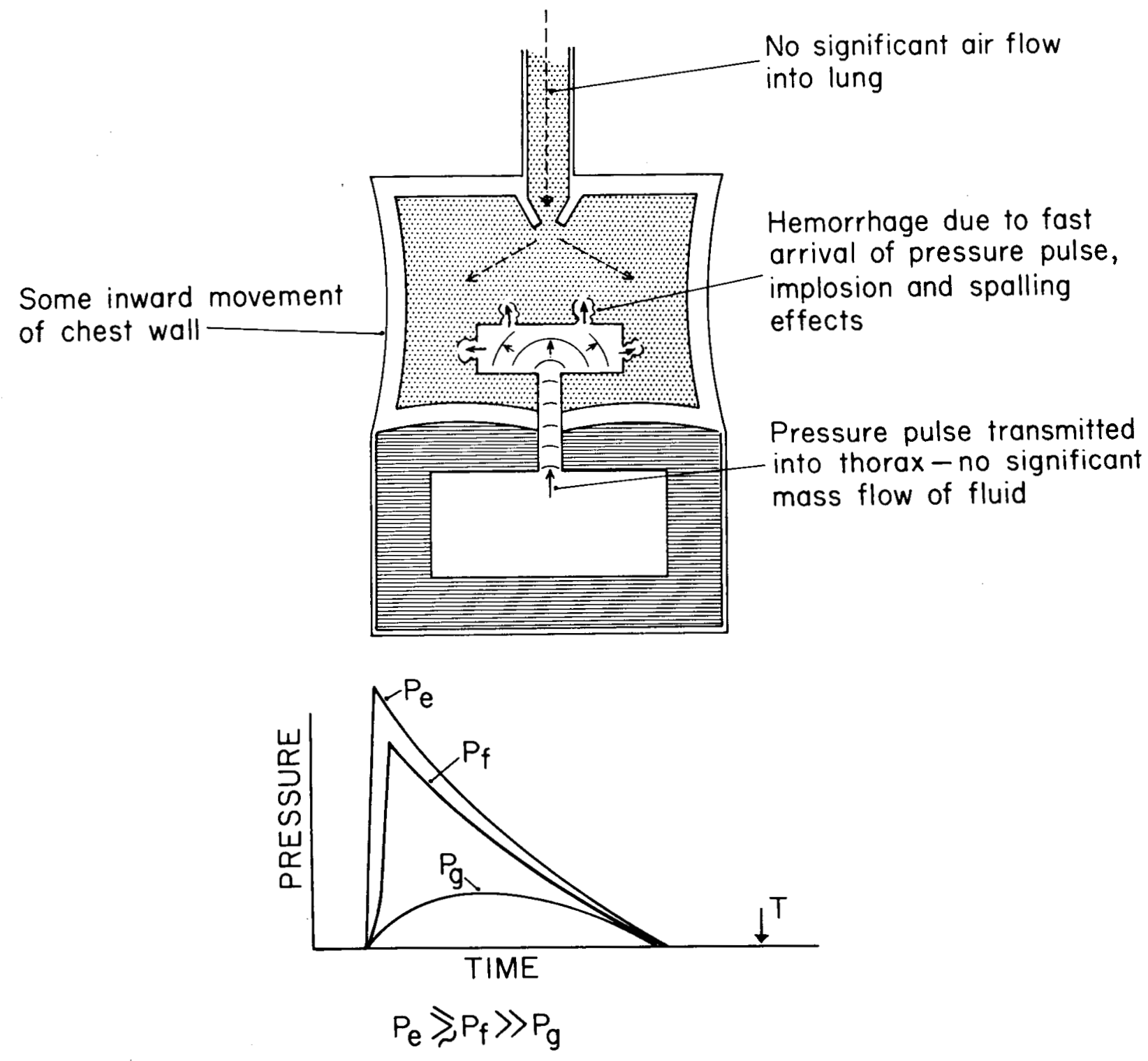

Figure 4. Diagram of model response to "fast"-rising overpressures of "short" duration. See text for discussion. 
in case air emboli occluded a large coronary vessel, cardiac arrest might occur early with pulmonary hemor rhage and edema a minimal finding at post mortem, a fact which has been described.

Figure 5 represents a similar situation to that in Figure 4, except the "instantaneous" (incident plus reflected) overpressure was imagined to be "high" and of "long" duration. All the events discussed above can likewise take place - spalling, implosion and fragmentation of alveolar and nea $\mathrm{r}-\mathrm{by}$ vascular areas - plus maximal decrease of thoracic volume to and beyond the residual volume with mass flow of fluid into the chest to increase hemorrhage and edema further. Also, it is possible to imagine that sufficient energy might be transferred to the walls of the thorax and abdominal contents to cause them to "over-shoot" in their inward movement with the development of internal thoracic pressures greater than those in the external environment. In such instances an oscillating pressure in the gaseous phase of the body might ensue as has been shown to occur in high-speed ballistic studies (25). The dotted line in Figure 5 was included to represent possible oscillations in the pressure of the gaseous phase of the lung. This extremely dangerous array of responses, dictated by the dynamic interplay of pressure "loading" and biological response, are far from simple and not easy to study in detail.

Before proceeding, it is appropriate to use the simple hydrostatic model for additional qualitative purposes to point out four other possibilities not yet discussed. The first concerns the rising phase of a single pressure pulse which may not only rise slowly or quickly in a single step but in a sawtooth or stepwise manner, a circumstance which can become quite complex and will be noted again below. The second deals with the falling phase of a pressure pulse which endures long enough for the gas density in the alveoli to become elevated to that in the environment. After this occurs, the animal is "cocked" for decompression-like pathology and whether such occurs or not is entirely dependent upon the magnitude, character and rate of pressure fall. Third, there is the possibility of multiple "loading" from pressure reflections, which contingency is frequently governed by the geometry of exposure. Not infrequently, in fact, oscillating pressure pulses reverbrate from one end of a blast "loaded" structure to the other (9). Exposure to such 


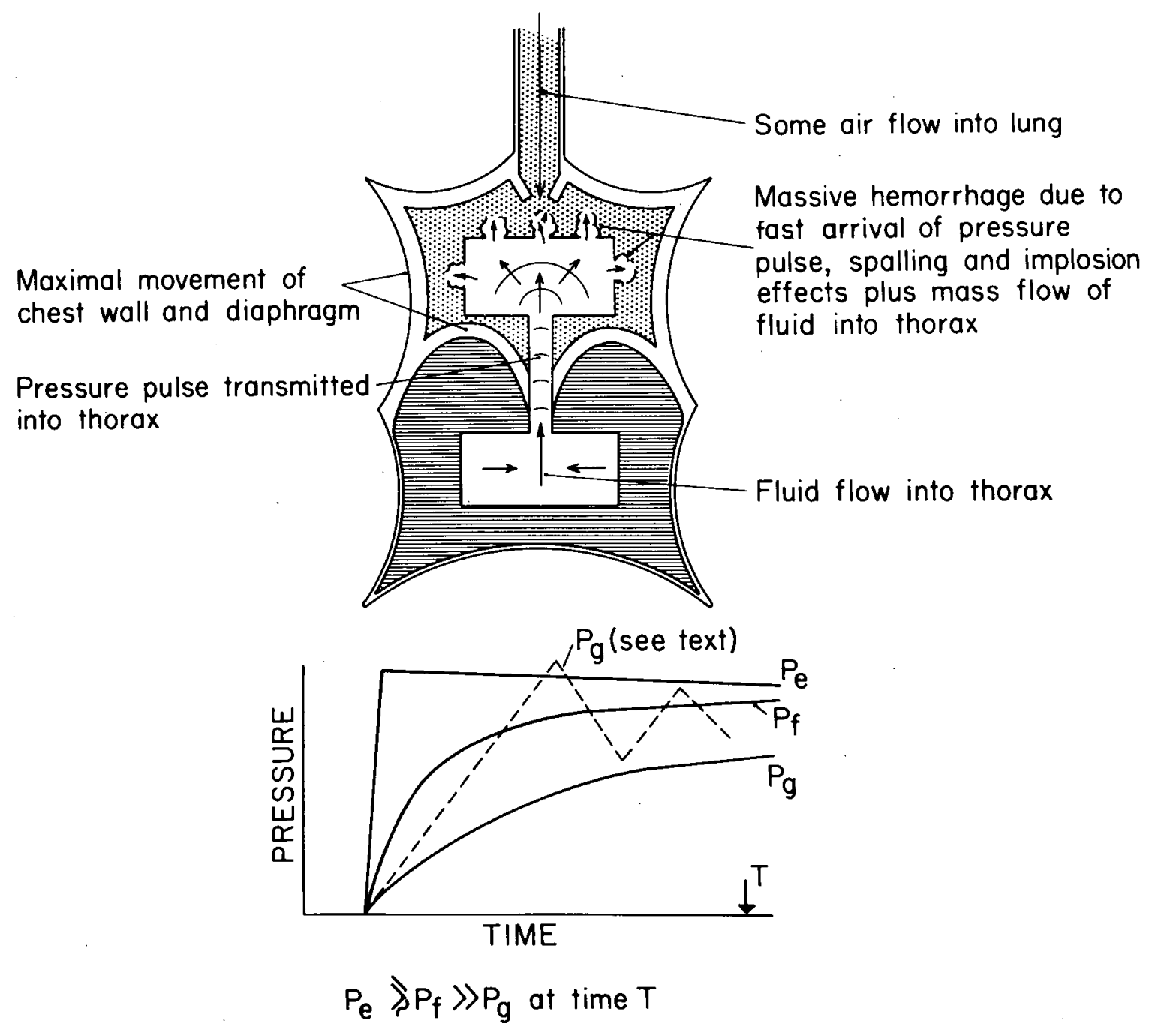

Figure 5. Diagram of model response to "fast"-rising overpressures of "long" duration. See text for discussion. 
environmental variations raises the question of the resonance of different portions and organs of the body, a subject that is far from understood, but under study in some laboratories $(26,27)$.

Fourth, there exists a possible chain of events which might involve gaseous supersaturation of the blood circulating through the lung - particularly the fast-diffusing carbon dioxide - associated with the rise of pressure in the alveoli. A consequence of this could be subsequent formation of gas eous emboli arising intravascularly in the systemic arterial circulation during and after the fall of gaseous pressure in the lung following the decrease in environmental pressure. Such an occurrence would aid interpreting the puzzling findings of Brown and Lee (28) who slowly pressurized mice to 80 psi, held them at that pressure for $1 \mathrm{~min}, 1 \mathrm{sec}$ and $100 \mathrm{msec}$, and then "dumped" the pressure back to the previous ambient in $30 \mathrm{msec}$. With holdtimes at $80 \mathrm{psi}$ of $1 \mathrm{~min}$ and $1 \mathrm{sec}$, the observed mortalities were 80 and 20 per cent, respectively. In contrast, no mortality was noted for hold-times of $100 \mathrm{msec}$ or less. The unlikely circumstance that the findings were due entirely to lung damage from rapid decompression, suggests that one should consider the physiology of rapid gas exchange. This in turn alerts one to the fact that the falling phase of blast-produced overpressure - particularly those of long duration - and the total time at overpressure should be fully appreciated by careful students of blast biology.

\section{Biologic Response}

Attention will now be directed to the gross biologic response to blastproduced variations in environmental pressures. The available data indicate that mammalian material in general (a) is less likely to be damaged by overpressures of "short" duration compared with those of "long" duration, and (b) is more tolerant to "slowly"-rising overpressures than to those developing almost instantaneously.

\section{Overpressures of "Short" Duration}

For example, Fisher, Krohn and Zuckerman $(29,30)$ in excellent studies using high explosives to produce "fast"-rising pressure pulses from 1 to $3 \mathrm{msec}$ in duration showed that the overpressures associated with 50 per 
cent mortality $\left(P_{50}\right)$ in mice, guinea pigs, rabbits, monkeys and goats were near 27, 32, 55, 100 and $200 \mathrm{psi}$, respectively. The authors related the $P_{50}$ data to the weight of the three smaller animal species by the equation

$$
P_{50}=0.24 \mathrm{~W}^{2 / 3}+23.7
$$

where

$$
\begin{aligned}
& P_{50}=\text { local static overpressure in psi } \\
& W \quad=\text { body weight in grams }
\end{aligned}
$$

From this relation the $P_{50}$ for the 60 and $80 \mathrm{kgm}$ man was predicted to be 390 and $470 \mathrm{psi}$, respectively. The same authors cited 12 human exposures to bombs dropped on British cities under circumstances wherein the pressure could be estimated. One fatality occured at $450 \mathrm{psi}$, but the re were 10 survivors at pressures between 170 and 450 psi and one between 500-600 psi.

Desaga (2) in Germany during the war noted two deaths among 13 men exposed in an open-topped concrete gun emplacement to blast from a high explosive bomb detonated close by. Estimates of the overpressure which occurred in a corner where the fatally injured men were located were said to involve an incident overpressure of $57 \mathrm{psi}$ which reflected to a maximum of 235 psi.

While it is true that the durations of the overpressures applicable to the British and German field observations were not stated, other data exist which suggest that both the peak overpressure and the duration are significant biologically as will be noted below. Thus, it is unlikely that there is any serious inconsistency between the field figures quoted above, but it is necessary to point out that these estimates of man's tole rance apply to high explosiveproduced overpressures which are "fast"-rising and of relatively "short" duration.

\section{The Overpressure-Duration Relationship}

Many years ago Hooker (1) stated that the duration of an overpressure was important in animal studies of the effects of blast pressures produced by 
mortars and large naval rifles. Much later Clemedson (7) claimed that both the magnitude of the overpressure and its duration were of significance in assessing the relation between pressure variation and biological response. Schardin (5) agreed as did Desaga (2).

The latter worker (2) set forth just fatal conditions for dogs in terms of the maximal local static pressures $\left(\mathrm{P}_{100}\right)$ and the durations of the overpressures produced using high explosives as noted in Table 2.

In the case of mice, a fairly recent study by Celander, et al. (31) is of significance. The results are summarized in Table 3.

From Tables 2 and 3, which show variations in mortality associated with changes in both the overpressures and durations of "fast"-rising relatively "short" pressure pulses, it is evident caution must be used in correlating biologic response with characteristics of a blast-produced pressure pulse. This is particularly true if one considers the pressure-time phenomena associated with nuclear explosives which may involve overpressure measured in hundreds of milliseconds to seconds in duration.

Indeed, it can be said that there has been no satisfactory, systematic studies of the pressure-duration relationships in investigations of blast pathology. Beyond the information in Tables 2 and 3, a few studies by Clemedson (7) using an impulse chamber to expose rabbits to fluctuating overpressures enduring for about $80 \mathrm{msec}$, and the data which will be given below dealing with overpressures lasting for $80 \mathrm{msec}$ up to $10 \mathrm{sec}$, no relevant data have appeared in the literature.

"Long"-duration Overpressures

Because of the need for studies applicable to nuclear explosions, experiments have been conducted for the United States Atomic Energy Commission both in the field and in the laboratory. In 1953 at the Nevada Test Site severe, though non-fatal, pulmonary damage was noted in dogs exposed to nuclearproduced overpressures ranging from 12 to 25 psi in magnitude and enduring for from about 500 to almost $800 \mathrm{msec}$ (9). Also, the findings indicated that the rate of pressure rise was of importance. 
Table 2. Pressure-Duration Relationship for Near 100 Per Cent Mortality in Dogs Exposed to Sharprising, "Short"-duration High Explosive Blast.

After Desaga (2)

\begin{tabular}{cc}
$\begin{array}{c}\text { Maximum static } \\
\text { overpressure } \\
\text { psi }\end{array}$ & $\begin{array}{c}\text { Overpressure } \\
\text { duration } \\
\text { msec }\end{array}$ \\
\hline 216 & 1.6 \\
218 & 1.6 \\
125 & 4.1 \\
85 & 8.6 \\
79 & 10.3 \\
76 & 11.8 \\
\hline
\end{tabular}

NOTE: Animals, lying on their sides with backs to the explosive, were exposed on level terrain to hemispherically molded charges detonated on the ground. 
Table 3. Pressure-Duration Relationships for the Indicated Mortality in Mice Exposed in a Shock Tube to Sharp-rising, "Short"-duration Overpressures. After Celander, et al. (31)

\begin{tabular}{|c|c|c|c|c|}
\hline \multicolumn{3}{|c|}{ Overpressure } & \multirow{2}{*}{$\begin{array}{l}\text { Number } \\
\text { animals } \\
\text { exposed }\end{array}$} & \multirow[b]{2}{*}{$\begin{array}{l}\text { Mortality } \\
\text { per cent }\end{array}$} \\
\hline $\begin{array}{l}\text { Static } \\
\text { psi } \\
\end{array}$ & $\begin{array}{c}\text { Reflected } \\
\text { psi }\end{array}$ & $\begin{array}{c}\text { Duration } \\
\text { msec* }\end{array}$ & & \\
\hline \multirow[t]{3}{*}{15} & 43 & 4.4 & 18 & 33 \\
\hline & & 1.9 & 10 & 20 \\
\hline & & $0.15 \pm 20 \%$ & 10 & 0 \\
\hline \multirow[t]{3}{*}{19} & 59 & 4.6 & 10 & 100 \\
\hline & & 1.9 & 10 & 50 \\
\hline & & $0.15 \pm 20 \%$ & 10 & 10 \\
\hline \multirow[t]{3}{*}{24} & 75 & 4.7 & 10 & 100 \\
\hline & & 2.0 & 15 & 87 \\
\hline & & $0.15 \pm 20 \%$ & 15 & 73 \\
\hline \multirow[t]{3}{*}{29} & 100 & 5.0 & 6 & 100 \\
\hline & & 2.1 & 15 & 93 \\
\hline & & $0.25 \pm 20 \%$ & 15 & 80 \\
\hline
\end{tabular}

* Times reported by Celander refer to the duration of the pressure plateau following the "instantaneous" rise in pressure and do not include the subsequent tail-off of the overpressure to the pre-exposure ambient.

NOTE: Animals, inside loosely woven bags placed on the floor of the shock tube, were exposed'nose-on to the advancing pressure pulse. 
Such observations prompted the design of laboratory tools to study "long"-duration overpressures rising "rapidly" and "slowly" to a maximum. Examples of data from each category will now be presented.

\section{"Fast"-rising overpressures}

Single-step pressure rise. Employing a laboratory pressure source with the test end closed with a metal plate and regulated leakage rates to control overpressure duration, four species of animals were exposed sideon in cages bolted to the end-plate of the tube $(13,14,32)$. Overpressures were created by the rupture of a diaphragm confining gas under pressure in a tank to which the tubular test cell was connected. The animals were "hit" almost simultaneously by the incident shock pressure travelling down the tube and its reflection from the end-plate. Except for a few experiments in which the overpressure duration was $80 \mathrm{msec}$, all pressures endured for 6 to $8 \mathrm{sec}$. The results are summarized in Table 4 from the work of Richmond, et al. (32).

Attention is directed to the overpressures associated with 50 per cent mortality noted in Table 4. It is apparent that a wide variation in the $P_{50}$ among the four species of animals was not noted and that tolerance did not strictly follow a trend with body weight. Consideration of the geometry of exposure and the animal-size relationship alluded to earliex requires one to reason that there might be a significant delay between the arrival of the incident pressure and its reflection which was different for the larger compared with the smaller animals; e.g., there might indeed be no instantaneous application of incident and reflected pressures in the experiments noted in Table 4.

Double-step pressure rise. To explore the possible significance of delay between arrival of the incident pressure and its subsequent reflection, experiments were done with guinea pigs in which the cage was located at various distances from the end-plate of the shock tube $(13,14,32)$. Thus, the animals were first "hit" with the "fast"-rising, incident pressure - which was maintained - and later by the "fast"-rising reflection; i.e., the rising phase of the pressure occurred in two steps instead of one.

Table 5 shows the surprising results and points out that merely moving the animal's cage a few inches from the reflecting surface increased the $P_{50}$ from about 37 to near $58 \mathrm{psi}$. In addition, the table shows that the 
Table 4. Mortality Data for "Fast"-rising, "Long"-duration Shock Tube-produced Overpressures when Incident and Reflected Pressures are Applied Almost Simultaneously $(13,14,32)$

\begin{tabular}{|c|c|c|c|c|c|c|c|}
\hline \multirow{3}{*}{$\begin{array}{l}\text { Species } \\
\text { of } \\
\text { animal* }\end{array}$} & \multirow{3}{*}{$\begin{array}{c}\text { Number } \\
\text { of } \\
\text { animals }\end{array}$} & \multicolumn{6}{|c|}{ Overpressure in psi for indicated mortality } \\
\hline & & \multicolumn{2}{|c|}{$1 \%$} & \multicolumn{2}{|c|}{$50 \%$} & \multicolumn{2}{|c|}{$\frac{99 \%}{99 \%}$} \\
\hline & & incident & reflected & incident & reflected in & ncident & reflected \\
\hline Mouse & 115 & 7 & 20 & 11 & $29.8 \pm 1.1 *$ & 15 & 44 \\
\hline Rabbit & 145 & 9 & 25 & 12 & $33.4 \pm 1.2$ & 15 & 44 \\
\hline Guinea pig & 140 & 10 & 28 & 13 & $36.7 \pm 0.7$ & 17 & 48 \\
\hline Rat & 55 & 10 & 28 & 14 & $38.7 \pm 0.6$ & 18 & 53 \\
\hline
\end{tabular}

* Mean body weights for mice, rabbits, guinea pigs and rats were $18.5 \pm 0.15,1732 \pm 35.8,437 \pm 3.3$ and $192 \pm 1.5 \mathrm{gms}$, respectively. * All plus or minus figures refer to the standard error of the mean. 
Table 5. Mortality Data for Guinea Pigs for "Fast"-rising, "Long"duration Shock Tube-produced Overpressures when the Incident and

Reflected Overpressures are Applied in Two Steps $(13,14,32)$

\begin{tabular}{ccccc}
\hline $\begin{array}{c}\text { Distance } \\
\text { from } \\
\text { end-plate } \\
\text { in. }\end{array}$ & $\begin{array}{c}\text { Number } \\
\text { of } \\
\text { animals }\end{array}$ & $\begin{array}{c}\text { Overpressures associated } \\
\text { with } 50 \text { per cent mortality } \\
\text { in psi }\end{array}$ & $\begin{array}{c}\text { Time between appli- } \\
\text { cation of incident \& } \\
\text { reflected pressures } \\
\text { msec }\end{array}$ \\
\hline 0 & 140 & 12.1 & $36.7 \pm 0.7 *$ & 0 \\
1 & 75 & 13.4 & $40.8 \pm 2.1$ & $0.10 * *$ \\
2 & 78 & 15.6 & $48.3 \pm 1.3$ & 0.20 \\
3 & 87 & 16.9 & $52.8 \pm 1.9$ & 0.30 \\
6 & 99 & 18.7 & $58.6 \pm 1.6$ & 0.63 \\
12 & 109 & 18.2 & $57.1 \pm 1.1$ & 1.36 \\
\hline
\end{tabular}

*All plus or minus figures refer to the standard error of the mean * Estimated 
mammalian organism has a surprising "ability" to distinguish time. as it is related to pressure variations, for 200 to $300 \mathrm{microsec}$ delay between the application of the first and second "fast" rise in the pressure pulse was associated with a change in the $P_{50}$ from near 37 to 48 and 53 psi, respectively.

To further elucidate the effects of rapid, stepwise rises in overpressures of "long" duration, Richmond, et al. (32) determined the mortality variations associated with similar exposure of the animals at different distances in front of a reflecting surface when the incident and reflected overpressures varied slightly above and below means of 17.8 and 52.1 psi, respectively. Mice, rats, guinea pigs and rabbits whose average weights were close to $19,190,435$ and $1730 \mathrm{gms}$, respectively, were used. The results are tabulated and summarized graphically in Figure 6 . There can be little doubt that mortality falls rapidly as the distance from the reflecting surface increases, which circumstance is associated with an increase in time between arrival of the incident and reflected pressure pulses. Also, it is clear from Figure 6 that the fall in lethality is related to the size of the animal. For the smaller species, a drop in mortality from 100 to near zero per cent occurred when the cages were moved from 2 to 3 in. from the reflecting surface. In contrast, a drop in mortality from 100 to between zero and 25 per cent was found for the larger animals when exposure was 6 or more inches from the end-plate.

Schardin (33) also noted a progressive fall in mortality in rats exposed below, but at increasing distances, from a reflecting surface placed near the end of a "closed" shock tube. The duration of the overpressures were not stated, but the rising pressures were sharp and occurred in two steps. Thus, there have been independent reports of the significance of stepwise increases in pressure.

Such findings not only suggest that the average rate of pressure rise is an important variable in blast biology - which fact will be discussed further below - but direct attention to the significance of the relationship between the

* A microsecond is one millionth of a second. 


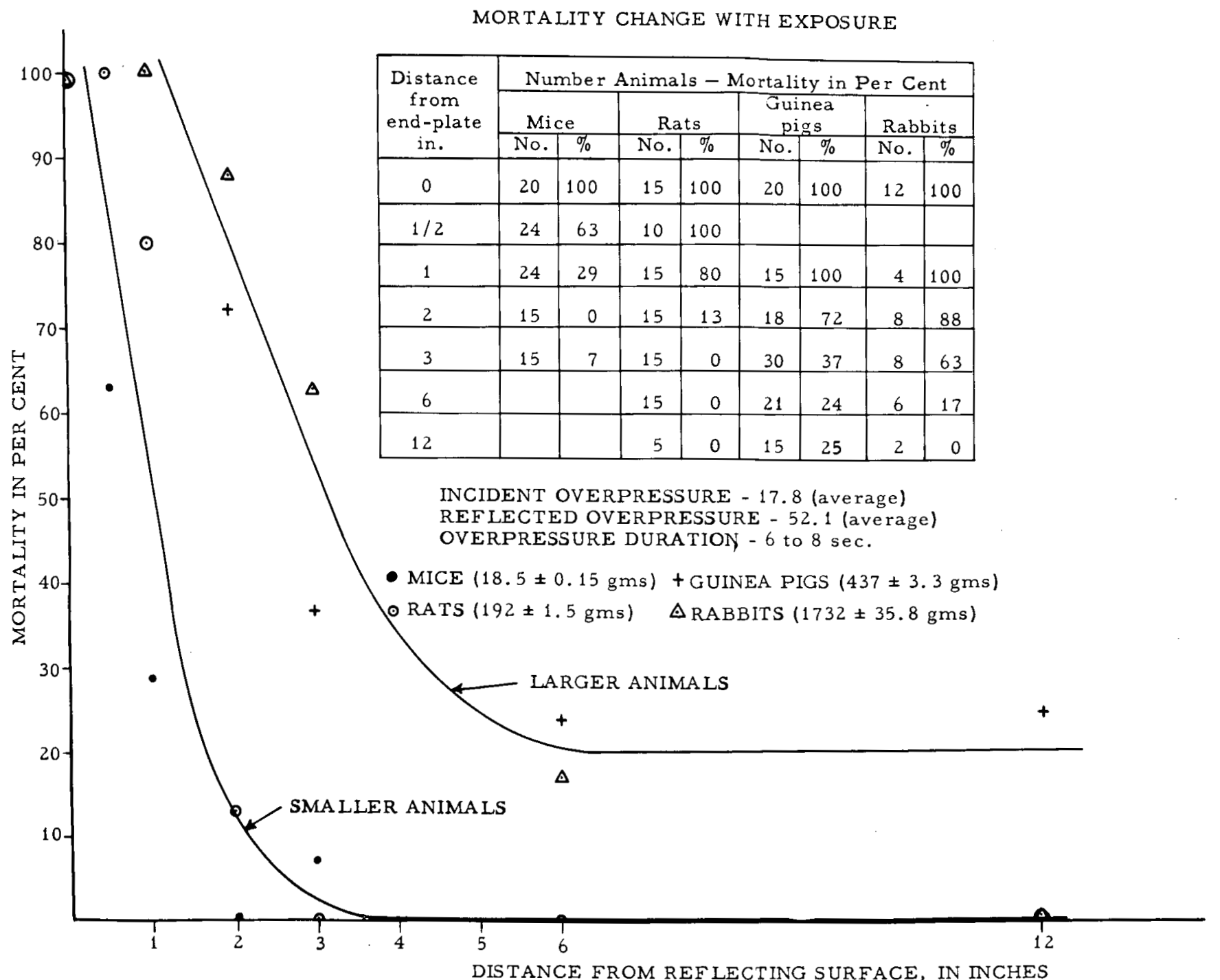

Figure 6. Mortality variations for animals exposed against and at indicated distances from the reflecting surface of a shock tube. Incident and reflected overpressures varied from 16.6 to 18.7 and 48 to 55 psi, respectively, and endured for 6 to $8 \mathrm{sec}$. 
magnitude of the incident and reflected pressures as these apply to different conditions of exposure.

For example, the animals studied in the "closed" shock tube - as would be the case in tunnels, basements and buildings of appropriate configurations - were "forced", so to speak, to "see" the maximum reflected overpressure. In contrast, animals exposed in the open would "see" only the incident plus the simultaneously-occurring pressure which actually reflected from the surface of their bodies. For a given incident pressure the magnitude of this pressure could hardly be that noted in the shock-tube studies since reflection is governed, among other things, by the angle at which reflection occurs and the size and consistency of the reflecting target, being maximal for large, hard surfaces placed perpendicular to the advancing shock front.

Apparent difficulties springing from such factors as those mentioned above are bound, therefore, to puzzle those who desire a reasonably quantitative understanding of biological blast effects. Precise elucidation of the relation between biologic response and the pattern of variation in environmental pressure as governed by geometry and various pressure sources from high explosives to shock tubes to atomic and hydrogen detonations - must await measurements which determine the pressure-time variations inside the organism as these are influenced by environmental pressure changes. Beginnings have been made (34), in the blast field, but data are as yet too meager to be helpful.

\section{"Slowly"-rising overpressures}

A few data are at hand to illustrate the previously mentioned fact that animals tolerate "slowly"-rising overpressures of long duration much bette $r$ than they do those rising "rapidly" in a single or double step. For example, in an exploratory study, Richmond, et al. (35) using a shock tube exposed dogs to various overpressures of 5 to $20 \mathrm{sec}$ duration in which the time to maximum pressure varied from about 30 to $150 \mathrm{msec}$. Table 6 shows the results.

The reader will note that even for overpressures as high as 150 to $170 \mathrm{psi}$ there was no mortality and that the lung hemorrhages found were slight. Actually, the latter, unlike the more spotty and often diffuse damage 
Table 6. The Effect on Dogs of "Slowly"-rising Overpressures of Long Duration. After Richmond, et al. (35)

\begin{tabular}{|c|c|c|c|c|c|c|}
\hline \multirow[b]{2}{*}{$\begin{array}{c}\text { Animal } \\
\text { weight } \\
\text { kg } \\
\end{array}$} & \multirow{2}{*}{$\begin{array}{c}\text { Max } \\
\text { over- } \\
\text { pressure } \\
\text { psi } \\
\end{array}$} & \multirow{2}{*}{$\begin{array}{c}\text { Time } \\
\text { to max } \\
\text { pressure } \\
\text { msec } \\
\end{array}$} & \multirow{2}{*}{$\begin{array}{c}\text { Duration } \\
\text { of over- } \\
\text { pressure } \\
\text { (sec)* }\end{array}$} & \multicolumn{3}{|c|}{ Pathology } \\
\hline & & & & $\begin{array}{l}\text { hemor- } \\
\text { rhagic } \\
\text { sinus } \\
\end{array}$ & $\begin{array}{l}\text { petechia } \\
\text { lining } \\
\text { larynx } \\
\end{array}$ & $\begin{array}{c}\text { pulmonary } \\
\text { hemorrhage }\end{array}$ \\
\hline 16.5 & 116 & 154 & 5 & + & + & - \\
\hline 17.9 & 147 & 158 & 5 & + & + & - \\
\hline 16.5 & 155 & 152 & 5 & $+t$ & + & - \\
\hline 16.7 & 167 & 155 & 5 & $+t$ & - & - \\
\hline 20.4 & 110 & 84 & 20 & + & + & - \\
\hline 19.3 & 118 & 85 & 20 & + & + & - \\
\hline 19.3 & 151 & 90 & 20 & $+t$ & - & + \\
\hline 15.6 & 156 & 86 & 20 & ++ & - & + \\
\hline 16.5 & 130 & 64 & 10 & + & - & + \\
\hline 20.8 & 160 & 60 & 10 & $+t$ & + & + \\
\hline 16.1 & 163 & 63 & 10 & ++ & + & + \\
\hline 19.5 & 170 & 60 & 10 & ++ & + & + \\
\hline 22.5 & 74 & 27 & 10 & + & - & - \\
\hline 20.2 & 86 & 28 & 10 & + & + & 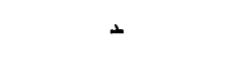 \\
\hline 18.1 & 112 & 30 & 10 & + & + & + \\
\hline 20.2 & 130 & 30 & 10 & + & + & + \\
\hline
\end{tabular}

* Approximate - measured with a stop watch

- Lesions not present

t Le sions slight

+t Lesions marked

NOTE: All eardrums were ruptured. 
noted with "fast"-rising overpressures, were almost entirely limited to the inferior margins of the lungs lying in the costophrenic sinuses. Apparently, the lungs were compressed between the inward-moving thoracic wall and the rising diaphragm due to implosion of the body wall causing narrow, wedgeshaped areas of hemorrhage along the caudal borders. Somewhat similar lesions have been described previously by Zuckerman $(6,36)$ in animals exposed "close" to small high explosive charges and explosions of hydrogenoxygen mixtures in balloons. Also, Osborn $(37,38)$ emphasized the occurrence of costophrenic lung lesions from nonpenetrating trauma to the lower thoracic borders along with damage to the liver and spleen often associated with such cases. This emphasizes the utility of chest $x$-rays in thoracic trauma, which if they reveal marginal wedge-shaped opacities, should alert the physician to the possibility of abdominal pathology and the frequent need for early surgery.

At this point it is well to pause and note, as was the case with the overpressure-duration relationship, there has been as yet no systematic investigation of the biologic significance of the character of the rising phase of the pressure pulse. Available data indicate that this is a critical parameter. It remains for future investigators to clarify the relative importance of variations in the average rates of pressure rise, stepwise and saw-tooth elevations in pressure with regard to the factors of magnitude and time, oscillating pressures, the falling phase of the overpressure under certain circumstances, the contributions made by exposure geometry, the size and mass of the biological target and the significance of the overpressure duration as biologically important variables. With regard to the last factor, there are reasons for believing that overpressure duration for single, "fast"-rising pulses, may be important over time intervals measured in hundreds of microseconds to a few milliseconds for smaller animals and over a few tens of milliseconds for the larger animals.

Such a statement can hardly apply to more "slowly"-rising overpressures or for those involving a series of abrupt rises, each of which is of insufficient magnitude and appropriately separated in time from its predecessor, to activate the "fast" biophysical mechanisms responsible for severe damage 
and fatality. Shock and pressure waves travelling in fluid and the more rapid inertia-sensitive responses happening in micro- and a few milliseconds simply cannot occur with "slower" rises in pressure. The latter type of pressure loading concerns "lazy" inertia-sensitive responses and perhaps the dynamics of gas exchange occurring in many tens of milliseconds, seconds and minutes.

Local Thoracic Trauma

In the early part of this century, Külbs (39) described bilateral lung hemorrhage in dogs subjected to unilateral blows delivered to the thoracic wall, particularly when the area traumatized was over the root of the lung. Daniel (40) in ballistic studies also reported severe lung hemorrhages, sometimes bilateral, associated with soft tissue wounds of the shoulder region of dogs produced with high-speed projectiles, even though the penetration pathway did not touch the lung or pleura. Harvey (41) suggested the internal pressure variations known to occur during and after wounding with a high-speed projectile, particularly the negative pressure associated with cavitation, not only could explain the findings of Daniel but had certain similarities with underwater blast.

Because local, nonpenetrating trauma involving sharp blows could cause pressure pulses to emanate from the point of impact and travel through tissue, as is the case in air blast, exploratory studies of the effects of nonpenetrating missiles striking the chest wall of dogs were undertaken (42). At "low" velocities hemorrhagic trauma is confined to the underlying lung, first appearing beneath the area of impact. Above this threshold, spotty isolated areas of hemorrhage on the surface and deep in the unilateral lung appear. At yet higher velocities such lesions are seen in the contra-lateral lung and the lung on the impact side becomes markedly hemorrhagic. Still higher velocities produce severe confluent bilateral lung hemorrhage. If the impact velocity is high enough, fatality occurs sometimes in a few minutes and the lung pathology is surprisingly similar to that noted in air blast. Table 7 summarizes some of the gross quantitative observations noted with 0.8 and $0.4 \mathrm{lb}$ nonpenetrating missiles 2.75 in. in diameter energized with an air gun and impacted against the lateral wall of dogs opposite the root of the lung. Death 
Table 7. Effects of Nonpenetrating Missiles Impacted Against the Lateral Thoracic Wall of Dogs. Data courtesy V. C. Goldizen (42)

\begin{tabular}{lcc}
\hline Biological effects observed & $\begin{array}{c}\text { Threshold velocities in ft/sec } \\
\text { for missiles of indicated weights }\end{array}$ \\
\hline$\frac{0.8 \mathrm{lb}}{0.4 \mathrm{lb}}$ \\
Lung hemorrhage & 45 & 80 \\
Unilateral side only & 110 & 125 \\
Bilateral & 60 & 120 \\
Rib fracture & & 120 \\
Internal lacerations from & 90 & 170 \\
rib fracture & 155 & \\
Fatality within 1 hr & & \\
\hline
\end{tabular}


has been noted in some animals in five or ten minutes after missile impact without rib fracture and with lung contusion, hemorrhage and edema the only positive findings at autopsy. The problem has been appreciated by others (43), but as yet no completely clear explanation of the cause of death has been uncovered.

As in air blast, the missile data suggest the need for quantitative studies of the pressure-time variations occurring inside the mammalian organism as one refined technique to unravel the biophysical events responsible for damage and fatality.

\section{Pathophysiologic Observations}

Even though the pathology associated with exposure to blast-produced overpressures has been well documented $(1-4,6,7,9,36,38,44)$ and available pathophysiological data have been discussed in an excellent recent review by Clemedson (16), there remains differences of opinion concerning the biophysical mechanisms at play along with interpretation of the events which lead to death. In the material which follows no attempt will be made to detail all the blast-produced lesions which have been described. Rather, attention will be directed briefly and in a selective manner to observations bearing upon the experimental data and cardiopulmonary findings of etiological significance, giving a few illustrative examples of pathology documented in the course of recent research.

\section{Conditions of exposure}

Some of the earlier experiments using animals exposed to high explosive-produced blast ("fast"-rising, "short"-duration overpressures) are illuminating as indicators of significant factors in the etiology of blast pathology. For example, if an animal is shielded from an otherwise fatal explosive charge by a steel box from which the head protrudes, there is no detectable damage $(3,6,36,45)$ providing the head and neck a re padded to avoid violent contact with the steel wall of the box $(6,36,45)$. This is so, even if a tracheotomy tube is attached to a funnel facing the charge (3), indicating that the propagation of the blast overpressures down the respiratory tree is not of primary significance. Other measures for protecting the trunk of the 
animal from the "blow" of the blast wave also gives protection as illustrated by such things as a rigid plaster of paris cover and appropriate padding with sponge rubber, but not a thin plaster bandage applied to the chest and abdomen to avoid overdistention of the thorax $(2,3,6,36,45)$. Such observations suggest that it is the impact of the blast wave and overpressure against the body wall that is critical $(3,36)$ and not the negative phase of the pressure pulse. This view is also supported by the protection offered by experimental pneumothorax which if unilateral or bilateral offers considerable protection to the lung on the side of the pneumothorax $(2,3)$.

Also, animals immersed hind feet first in water to the diaphragm and exposed to an underwater charge show only abdominal pathology. When immersion of the abdomen and thorax is arranged, there is abdominal damage and also pulmonary lesions plus signs of central nervous system origin (3). These facts and those above, along with electrocardiographic signs of anoxic cardiac disturbances, suggest that gaseous emboli arising in the chest during or subsequent to the blast and migrating via the circulation to the heart and central nervous system might be one important pathophysiological event that could well prove fatal of itself.

\section{Causes of death}

Air emboli, hemorrhage and edema. With regard to the occurrence of air emboli in mammals exposed to blasts, a number of findings are of interest. First, air emboli, not noted before 1942 - and since by some workers - have been visualized by many investigators on the arterial side of the circulation in dogs $(2,3,4,42)$, rabbits $(42,47)$, guinea pigs (42), rats (42), and man (4) exposed to blast overpressures. As might be expected from the work with experimental air emboli - which has demonstrated that (a) injected air migrates to the most superior portions of the vascular system and the consequence to the animal is largely influenced by body position, and (b) the detailed anatomy involved and blood flow as well as the amount of intravascular gas are of considerable significance - there have been inconsistencies in reports visualizing air in animals fatally exposed to blast. Too, there is an element of chance in certain experiments wherein a single air embolus may migrate into a large coronary vessel or vital area of the central nervous 
system with death resulting in a few minutes. Almost immediate signs of severe and progressive anoxia of the myocardium demonstrable with the electrocardiogram are seen, both in blast and experimental arterial air embolism, with death often following fibrillation that develops fairly quickly. In such cases there is only a remote possibility of visualizing intravascular air at necroscopy.

In contrast, animals severely injured from blast that do not die immediately apparently suffer various degrees of broncho- or alveolarvenous fistulas through which air may enter the pulmonary venous circulation with each respiratory cycle "pumping" additional air into the circulation. The result can be massive air embolism involving the heart, brain and other organs. Further, it is important to recognize that under circumstances of moderate lung damage, pulmonary vasoconstriction and hemorrhage - particularly the latter - can act protectively in that the fluid "seals" the alveolaror broncho-venous fistulas. An animal so situated may escape immediate death from emboli, but then faces the dangers from continued hemorrhage and edema. To these two factors, which in themselves embarrass the pulmonary circulation, are added the additional effects of transient circulatory arrest $(2,45)$, bradycardia $(2,3,7,16)$, lowered systemic arterial pressure $(1,3,7,52)$, vasoconstriction $(12,16,51)$, followed by vasodilatation $(51)$, increased venous pressure (53), and non-fatal, acute insult to the heart, signs of which are known to persist $(2,7,53)$ in some cases for days in animals $(2$, $3,7,16)$ and $\operatorname{man}(2,53,54)$.

To emphasize some of the above statements it is helpful to pause and consider data gathered in the course of the recent experiments described earlier.

First, regarding common findings in dogs, Figure 7 shows a photograph of the heart of a female Dalmatian weighing $16.8 \mathrm{~kg}$ exposed sideon against a reflecting surface in a shock tube to "fast"-rising, "long"-duration overpressure. The reflected pressure was 40 psi. The animal died within 8 min. Frank blood was noted coming from the nares and mouth. Air emboli were observed in the arteries of the heart, as can be seen in Figure 7, and in the brain. There was extensive pulmonary hemorrhage. The frontal sinus 

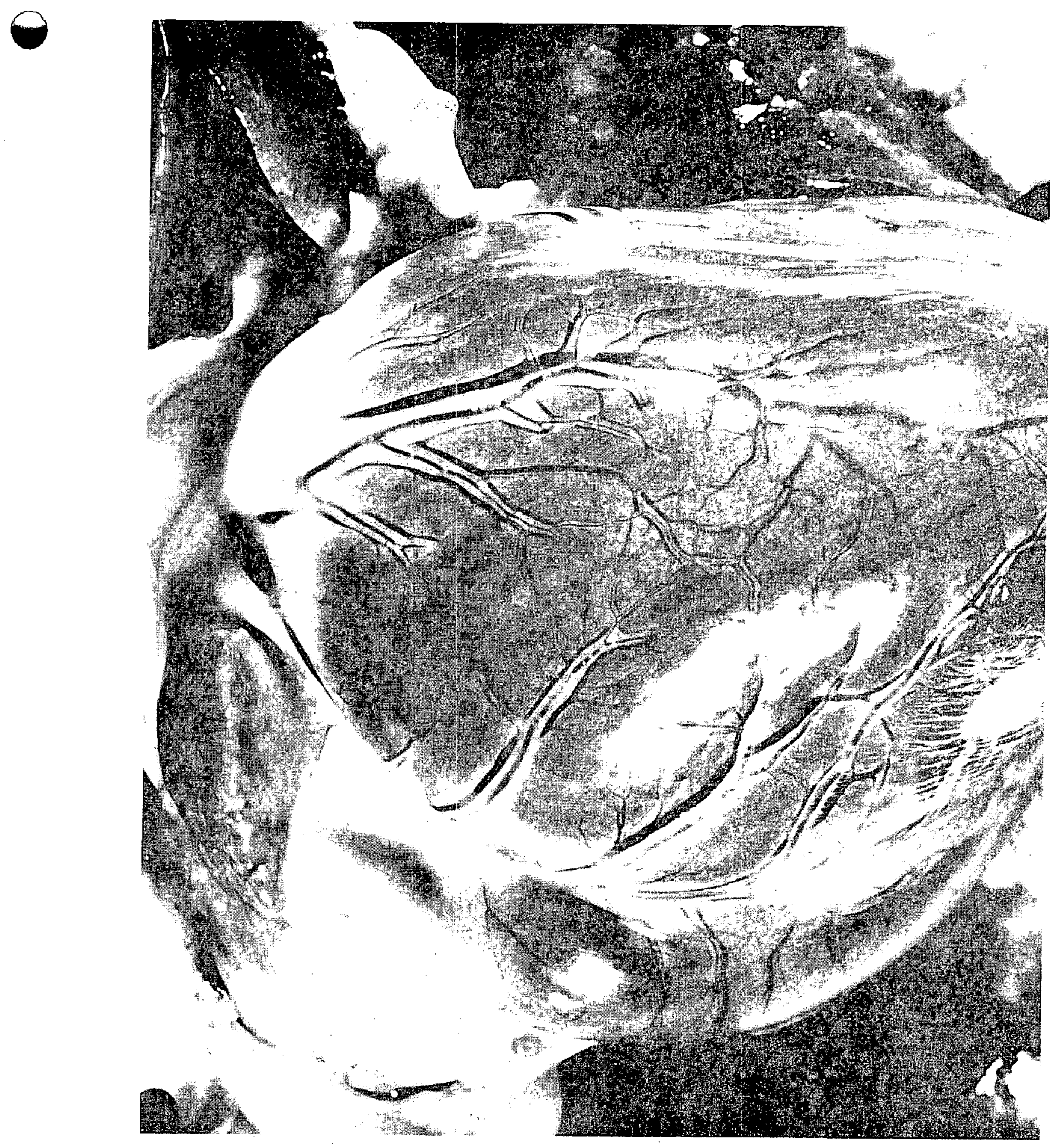

Figure 7. Heart of fatally injured dog exposed in a shock tube to a reflected pressure of 40 psi enduring for 6 to 8 sec. Note air emboli in the larger and smaller cardiac arteries. 
and larynx were also hemorrhagic. Both eardrums were ruptured.

Another Dalmatian female, weighing $14.8 \mathrm{~kg}$ and similarly exposed to a "fast"-rising overpressure reflecting to $39 \mathrm{psi}$, also died in 8 min with similar findings. Figure 8 shows an enlarged photograph of the coronary vessels containing copious amounts of air in different branches of the coronary arteries.

Table 8 details a sample of experience with guinea pigs during experiments done to establish mortality curves, from which some of the data in Table 5 were prepared. The table exemplifies the relation between mortality and reflected overpressure for "long" duration overpressures having single- or double-step "fast"-rising components and shows the related incidence of coronary air embolism as visualized grossly at post mortem examination. No surviving animal exhibited air emboli on sacrifice. In contrast, the incidence of air emboli in animals fatally injured progressively rose with increasing overpressure and mortality, to between 80 and 100 per cent for the 100 per cent mortality groups. Though there appears to be a species difference, similar findings have been noted at Albuquerque in rats, dogs and rabbits, but not in mice. To our knowledge no investigator has yet reported visualization of air emboli in the mouse - perhaps because of the small caliber of the vessels. However, the data in Table 8 serves to confirm and extend the earlier observations made in this country (48), Germany $(2,3,4)$ and Sweden (47).

Second, it is helpful to consider additional information from experiments with guinea pigs, to set forth the relation between the lung weight as a percentage of body weight - in surviving animals and in those fatally injured by single- or double-step, "fast"-rising, "long"-duration overpressures. Figure 9 shows data from 556 guinea pigs, giving the lung weights for the surviving animals in the lower and those for fatally injured animals in the upper portions of the figure. Also noted are the instances of coronary air emboli in the animals that died. The vertical lines delineating the areas 0 , I, II, III, IV \& V, labelled lung damage index, were drawn purely a rbitrarily as an exercise to explore the possibilities of using lung weight change as a "biologic dosimeter" for blast damage. The data are summarized in tabular form in 


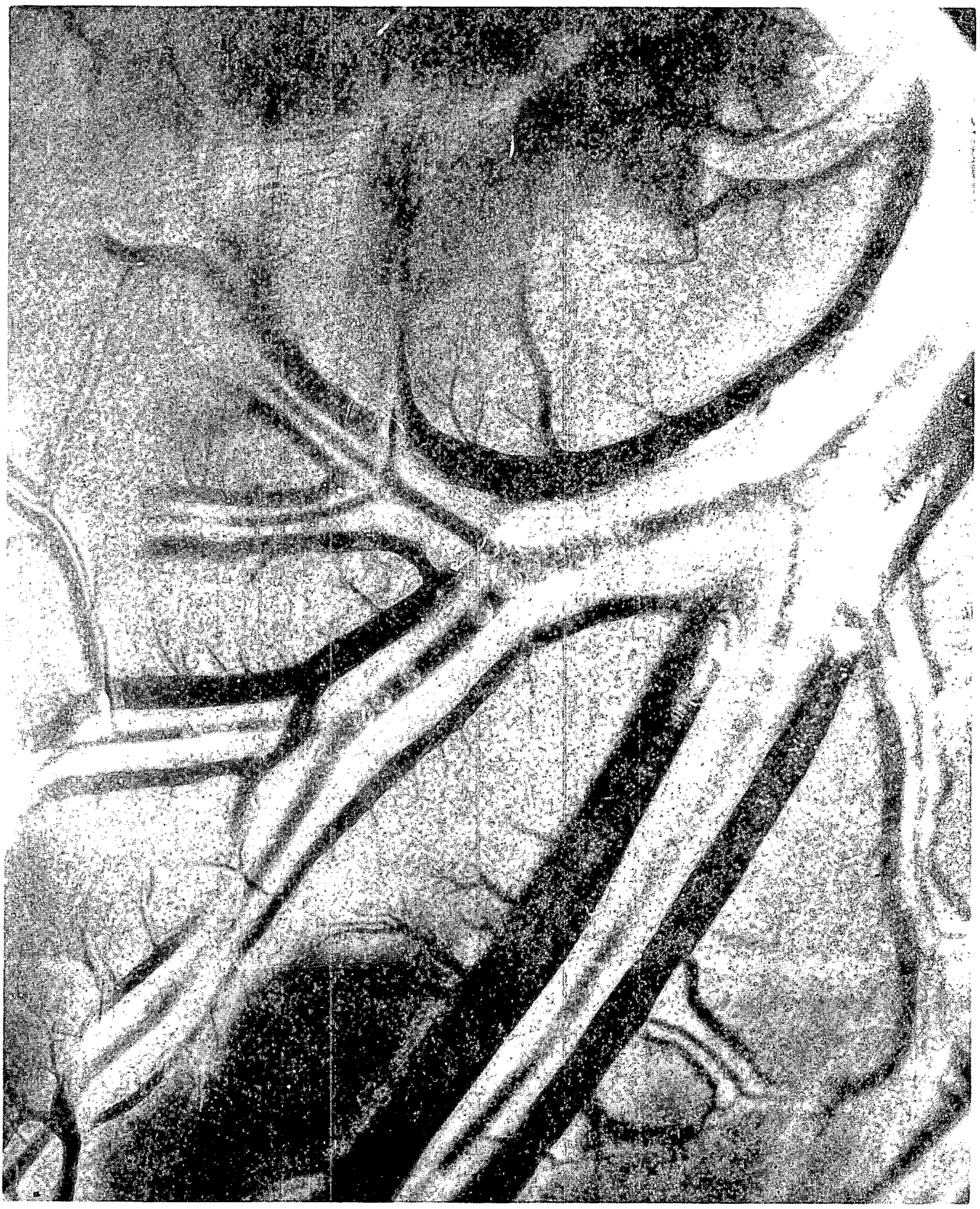

Figure 8. Enlarged view of coronary vessels of a dog fatally injured by a shock tube-produced, reflected overpressure of 39 psi enduring for 6 to $8 \mathrm{sec}$. Note gas bubbles in the larger coronary arteries and apparent breaks in the blood columns of the smaller vessels due to displacement of blood by intravas cular gas. 
Table 8. Mortality as Related to the Magnitude of the Reflected Shock Front for Guinea Pigs Exposed Side-on at Various

Distances from the End-plate of a Shock Tube

\begin{tabular}{|c|c|c|c|c|}
\hline $\begin{array}{c}\text { Distance of cage } \\
\text { from end-plate } \\
\text { (in.) }\end{array}$ & $\begin{array}{c}\text { Number of } \\
\text { animals }\end{array}$ & $\begin{array}{c}\text { Reflected } \\
\text { overpressure } \\
\text { (psi) }\end{array}$ & $\begin{array}{l}\text { Mortality } \\
\text { (percent) }\end{array}$ & $\begin{array}{c}\text { Number dead } \\
\text { with air emboli } \\
\text { (percent) }\end{array}$ \\
\hline \multirow[t]{8}{*}{0} & 15 & 16.3 & $0(0 / 15)$ & $0(0 / 0)$ \\
\hline & 15 & 20.7 & $0(0 / 15)$ & $0(0 / 0)$ \\
\hline & 20 & 29.3 & $5(1 / 20)$ & $100(1 / 1)$ \\
\hline & 20 & 36.3 & $40(8 / 20)$ & $50(4 / 8)$ \\
\hline & 25 & 39.6 & $76(19 / 25)$ & $63.2(12 / 19)$ \\
\hline & 15 & 42.0 & $86.7(13 / 15)$ & $53.8(7 / 13)$ \\
\hline & 15 & 46.7 & $100(15 / 15)$ & $86.7(13 / 15)$ \\
\hline & 15 & 55.3 & $100(15 / 15)$ & $80.0(12 / 15)$ \\
\hline \multirow[t]{5}{*}{1} & 21 & 31.1 & $14.3(3 / 21)$ & $33.3(1 / 3)$ \\
\hline & 15 & 37.0 & $13.3(2 / 15)$ & $50(1 / 2)$ \\
\hline & 15 & 42.0 & $40.0(6 / 15)$ & $66.7(4 / 6)$ \\
\hline & 12 & 45.9 & $83.3(10 / 12)$ & $90(9 / 10)$ \\
\hline & 12 & 52.0 & $100(12 / 12)$ & $83.3(10 / 12)$ \\
\hline \multirow[t]{7}{*}{2} & 12 & 39.3 & $8.3(1 / 12)$ & $0(0 / 1)$ \\
\hline & 12 & 42.9 & $25(3 / 12)$ & $33.3(1 / 3)$ \\
\hline & 18 & 48.8 & $55.6(10 / 18)$ & $90(9 / 10)$ \\
\hline & 12 & 52.0 & $66.7(8 / 12)$ & $62.5(5 / 8)$ \\
\hline & 9 & 58.0 & $77.8(7 / 9)$ & $100(7 / 7)$ \\
\hline & 6 & 71.0 & $100(6 / 6)$ & $83.3(5 / 6)$ \\
\hline & 9 & 77.3 & $100(9 / 9)$ & $100(9 / 9)$ \\
\hline \multirow[t]{7}{*}{3} & 9 & 37.7 & $0(0 / 9)$ & $0(0 / 0)$ \\
\hline & 12 & 48.1 & $25(3 / 12)$ & $66.7(2 / 3)^{+}$ \\
\hline & 15 & 50.6 & $26.7(4 / 15)$ & $66.7(2 / 3)^{+}$ \\
\hline & 15 & 52.6 & $53.3(8 / 15)$ & $60(3 / 5)^{+}$ \\
\hline & 9 & 56.7 & $77.8(7 / 9)$ & $60(3 / 5)^{+}$ \\
\hline & 15 & 60.8 & $86.7(13 / 15)$ & $80(4 / 5)^{+}$ \\
\hline & 12 & 73.5 & $91.7(11 / 12)$ & $100(5 / 5)^{+}$ \\
\hline
\end{tabular}

${ }^{+}$All dead animals were not dissected after death. Overpressures endured for 6 to $8 \mathrm{sec}$. 
LUNG WEIGHTS, MORTALITY ANO CORONARY

AIR EMBOLISM IN BLASTED GUINEA PIGS

Exposed against and various distances from plate closing end of a shock tube to $6-8$ sec rapidly in single or double steps.

$\frac{1}{1}$
Total number of animals - 556

Surviving animals - no coronary air emboli found at necropsy

Died - coronary air emboli not seen at necropsy

- Died - coronary air emboli visualized at necropsy

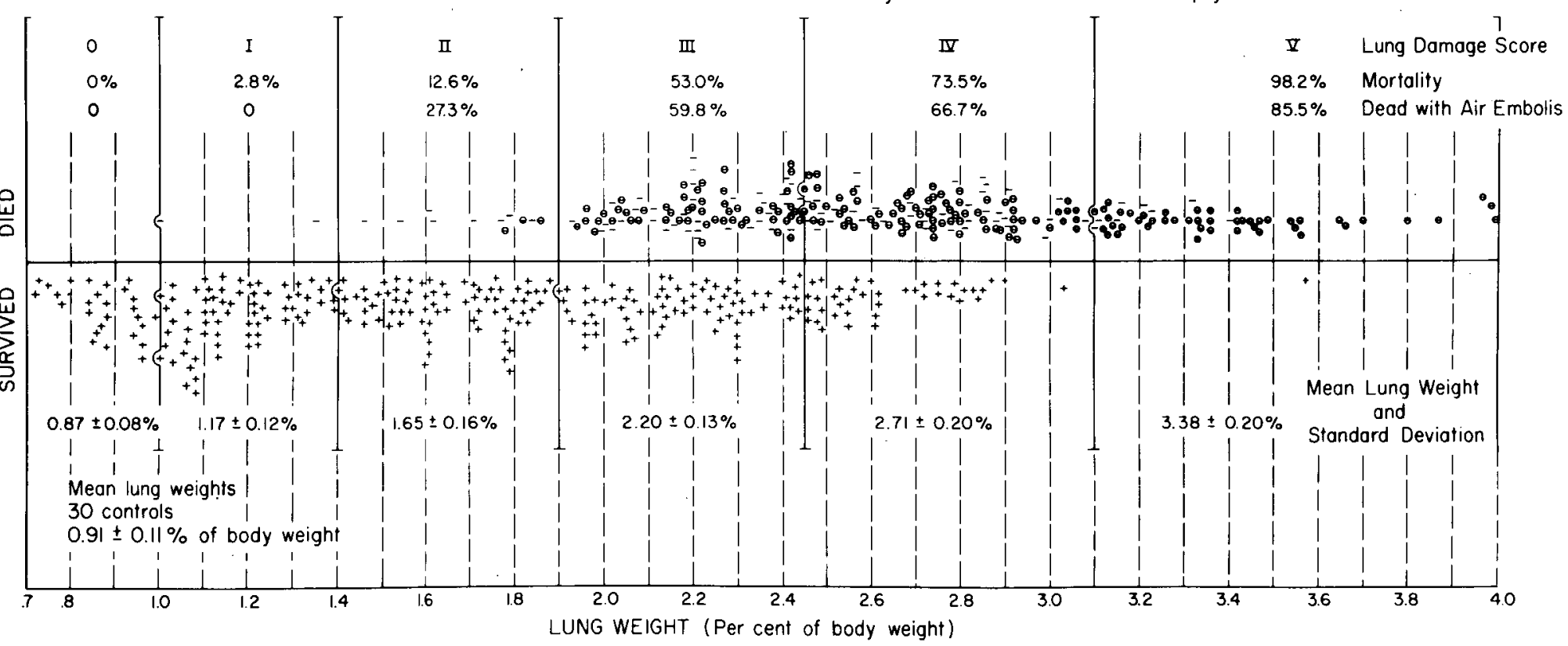

Figure 9. The relation between lung weight, mortality and coronary air embolism in guinea pigs surviving and fatally injured by "fast"-rising, shock tube-produced overpressures of 6 to 8 sec duration. Lung damage score groups were divided arbitrarily. See text. 
Table 9 .

For the technique employed in dissecting the guinea pigs, the mean lung weight as a percent of body weight in 30 animals was 0.91 per cent $( \pm 0.11$ $\mathrm{SD}$ and $\pm 0.02 \mathrm{SE})$. This figure adds interest to the group marked " 0 " to the left in Figure 9 because the mean per cent lung weight was 0.87 ( $\pm 0.01 \mathrm{SE}$ ). This fact gives indirect, though not statistically significant, confirmation to the pulmonary vasoconstriction which is said to follow exposure to blast (16) and which has been reported to endure in mice for about 15 to $20 \mathrm{~min}$ (12). Too, vasoconstriction has been observed directly in in-vivo studies involving experimental air emboli (51).

The observations on air emboli and increase in lung weight due to hemorrhage and edema reported above confirm and extend similar, previous observations $(2-4,7,12,16,55)$.

There remains yet another group of indirect, but most significant observations bearing upon the existence of air emboli in animals exposed to blast. These findings concern reports that: (a) electrocardiographic evidence of hypoxia and myocardial damage, which appear after exposure of animals to blast, can be reversed by use of a compression chamber $(3,47)$, (b) animals, otherwise fatally injured by blast, can be saved but not invariably so by immediate compression $(3,47)$, (c) the electrocardiographic changes following arterial air emboli are similar in $\operatorname{man}(2)$ and animals $(3,7,47,49,50,53)$ to the findings after exposure to blast, and (d) compression markedly improves the electrocardiographic signs of coronary malfunction produced by experimental arterial air emboli (3).

Heart. In addition to damage to the heart directly from coronary air embolism and indirectly from pulmonary hemorrhage, edema and the subsequent anoxia and dilatation, the re apparently occurs significant bruising of the heart sometimes noted under the term "commotio cordis" $(2,3,9,16)$. Internal and external hemorrhagic areas and bruising of the epicardium and myocardium, rarely rupture (57), do occur, but are said to account for only a small percentage of early fatalities $(2,3)$.

As an example, Figure 10 shows a bruised area of the myocardium 
Table 9. Association Observed in Blasted Guinea Pigs Between Mortality, Incidence of Coronary Air Embolism, Lung

Weight and Arbitrarily Fixed Lung Damage Score*

\begin{tabular}{|c|c|c|c|c|c|c|c|}
\hline \multirow{2}{*}{$\begin{array}{l}\text { Lung } \\
\text { damage } \\
\text { score }\end{array}$} & \multirow{2}{*}{$\begin{array}{c}\text { Total } \\
\text { number } \\
\text { animals }\end{array}$} & \multicolumn{4}{|c|}{ Lung weight as $\%$ of body wt. $* *$} & \multirow{2}{*}{$\begin{array}{l}\text { Mortality } \\
\text { per cent }\end{array}$} & \multirow{2}{*}{$\begin{array}{c}\text { Coronary air } \\
\text { embolism } \\
\text { per cent }\end{array}$} \\
\hline & & range & mean & $\overline{S D}$ & $\mathrm{SE}$ & & \\
\hline 0 & 27 & $<1.00$ & .87 & .08 & .02 & 0 & 0 \\
\hline I & 71 & $1.00-1.39$ & 1.17 & .12 & .01 & 2.8 & 0 \\
\hline II & 87 & $1.40-1.89$ & 1.65 & .16 & .02 & 12.6 & 27.3 \\
\hline III & 164 & $1.90-2.44$ & 2.20 & .13 & .01 & 53.0 & 59.8 \\
\hline IV & 151 & $2.45-3.09$ & 2.71 & .20 & .02 & 73.5 & 66.7 \\
\hline V & 56 & $>3.10$ & 3.38 & .20 & .03 & 98.2 & 85.5 \\
\hline Tota1 & 556 & & & & & & \\
\hline
\end{tabular}

* Animals exposed against and at various distances from plate closing end of shock tube to 6-8 sec duration overpressures rising rapidly in single or double steps.

** Mean lung weight ( 30 control animals) $0.91 \pm 0.11$ per cent of body weight.

+ Refers to mortality within $1 \mathrm{hr}$.

++ Computed as per cent of fatally injured animals.

$\mathrm{SD}=$ Standard deviation of the mean

$\mathrm{SE}=$ Standard error of the mean 


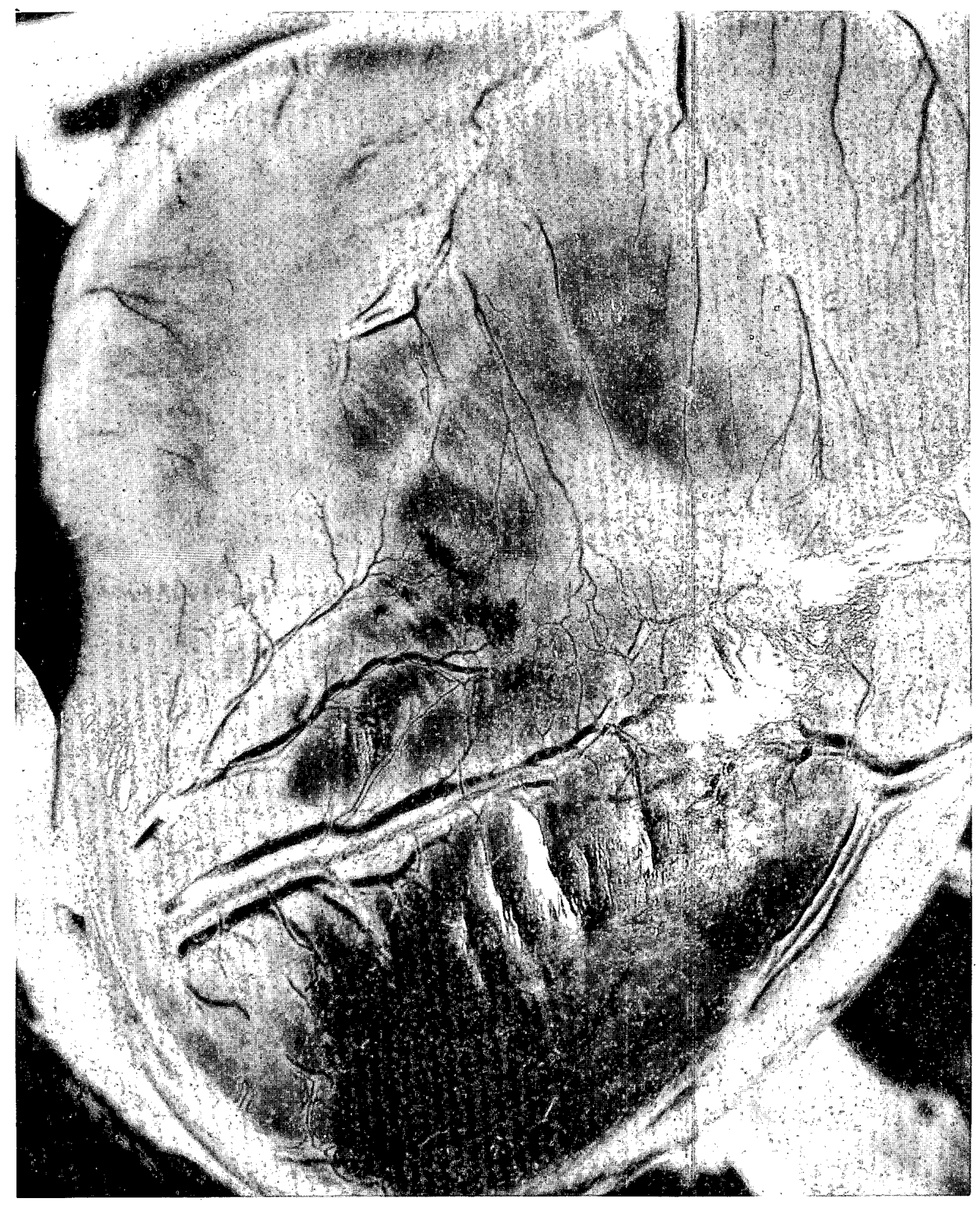

Figure 10. Enlarged view of bruised and hemorrhagic area of the myocardium of a dog fatally injured by a "fast"-rising shock tube-produced overpressure of 40 psi (reflected) enduring for 6 to $8 \mathrm{sec}$. Massive arterial air embolism is also easily seen. 
in a fatally injured dog exposed in a shock tube to a reflected pressure of 40 psi. Figure 11, a photograph of the lungs of a non-fatally injured dog exposed to 24 psi reflected overpressure, is of interest because it beautifully illus trates the type of lung pathology noted at the contact between the heart and lungs. The events which can take place at air-fluid junctions due to differences in tissue density have been alluded to earlier. These, of course, can damage both the heart and the lung. In the former case, the pathological signs and the immediate and persistent electrocardiographic findings can be, in part, reflections of such injury and may involve early fatality or delayed effects in surviving animals. It is difficult, if not impossible under certain specific circumstances, to establish whether the critical etiologic factors involve air emboli or commotio cordis as the single cause of death or malfunction, if indeed, such is the case. However, it is clear that both effects can occur together and it might be said that any attempt at segregating a cause of early death is academic. However, it is important to know the character of the basic lesion or lesions because such information bears upon the therapy of blast cases as will be discussed later.

Central nervous system. Various signs of focal damage to the central nervous system have been described involving lethargy and paralysis of the posterior extremities by Hooker (1), ataxia (42), and a variety of other symptoms observed by Benzinger in classical form in water blast where the animals heads were not immersed (3); e.g., the head was the superior portion of the body. Krohn, et al. (45) reported delayed electroencephalographic signs of circulatory disturbances or cerebral hypoxia in monkeys exposed to blast. From what is known today, air embolic insult to the central nervous systems offers adequate explanation of nervous symptoms and pathology $(2,3$, $4,47-51)$, and it is doubtful that the mechanism involving transmission of hydrostatic shock waves from the body fluids into the closed cranium described by Young (56) plays a significant role. Be this as it may, it is conceivable that air embolism to vital nervous centers, particularly in animals exposed to blast with the head uppermost, can contribute to early death as well as to delayed focal signs.

Genera1. Though no precise explanations of the causes of death and the etiologic events applicable to blast can be set forth, it appears clear, 


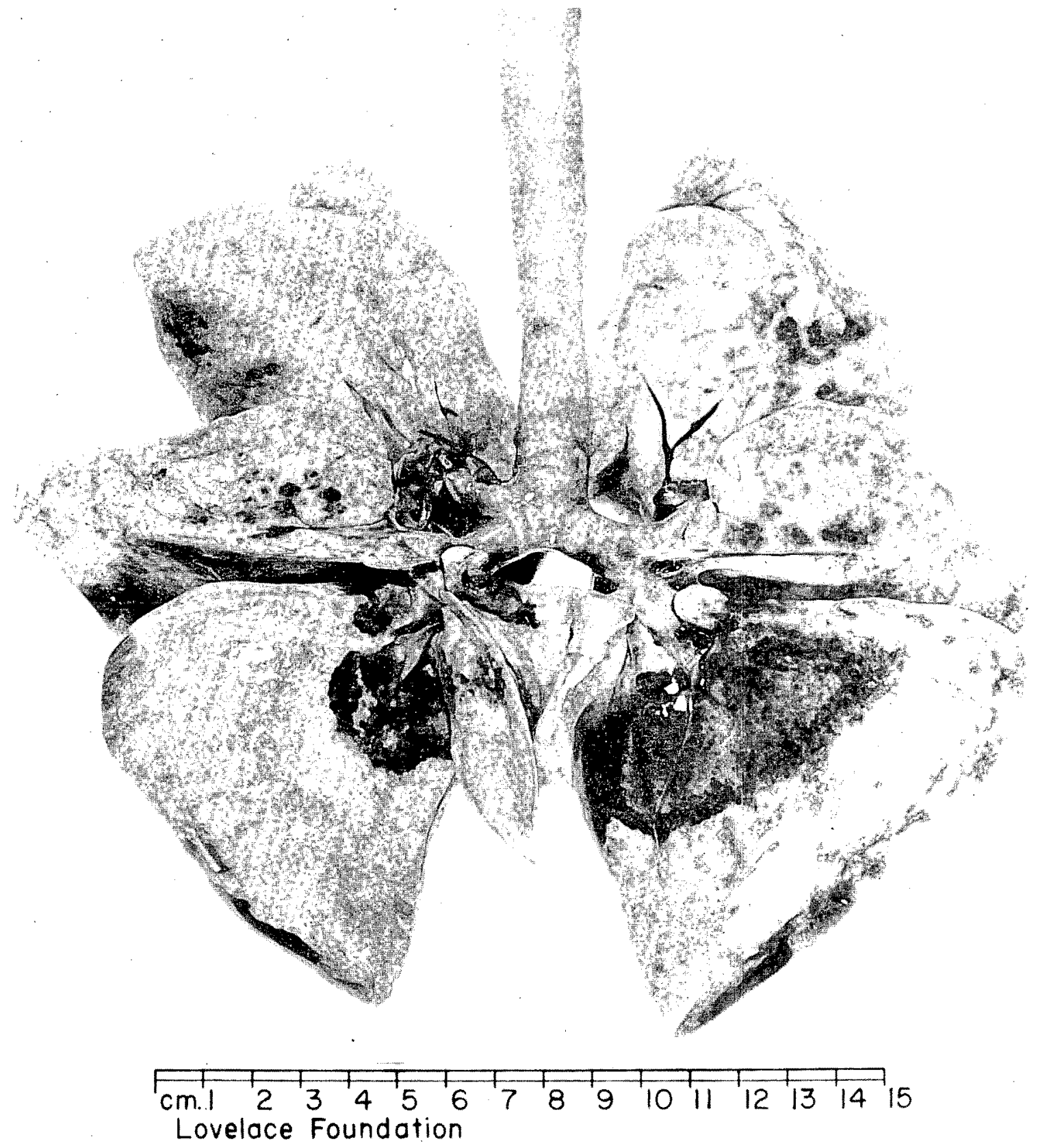

Figure 11. Ventral view of lungs of a dog non-fatally injured by a sharp-rising shock tube-produced overpressure of 24 psi (reflected) of 6 to $8 \mathrm{sec}$ duration. Note the area of hemorrhage in the lungs that were in contact with the heart. 
however, that: (a) direct damage to the heart can, but rarely does, cause fatality almost immediately; (b) coronary air emboli can and do produce almost immediate death, but typically the fatally injured animal expires in a matter of minutes usually from 2 to $10 \mathrm{~min}$ - rarely lives 15 to $20 \mathrm{~min}$; (c) suffocation due to hemorrhage and edema with concomitant hypoxia probably produces fatality in a somewhat longer period, though it is not common for animals who survive 15 to $20 \mathrm{~min}$ to succumb later; (d) malfunction of vital centers of the central nervous system may be a factor in early death from massive air embolism which is to be distinguished from damage due to frank physical head trauma, and last (e) the animal escaping early death may face the challenge of delayed complications from post-concussion pneumonia, perforations of the abdominal viscera, peritonitis, prolonged coronary signs with possible infarction and persistent local areas of damage in the central nervous system.

\section{"Slowly"-rising overpressures}

In a previous section the marginal lung hemorrhages commonly seen in animals exposed to "slowly"-rising overpressures of long duration were mentioned. Figure $12 \mathrm{a}$ and $\mathrm{b}$ are photographs of the dorsal and ventral views, respectively, of the lungs of an animal subjected to a "slowly"-rising overpressure of $170 \mathrm{psi}$. Figure $12 \mathrm{c}$ and d show normal lungs for comparison. In contrast, the massive lung hemorrhages produced by a "fast"-rising overpressure are shown in Figure $13 \mathrm{a}$ which depicts the lungs of a dog fatally injured by a "fast"-rising overpressure reflecting to a maximum of 44 psi. Figure 13b, a photograph of the lungs of a pig fatally injured at the Nevada Test Site, is shown to illustrate rib markings, massive hemorrhage and atelectasis of one lobe.

\section{Local trauma}

The unilateral and bilateral lung hemorrhage occurring from unilateral impact of nonpenetrating missiles is illustrated in Figure $13 \mathrm{c}$ and $\mathrm{d}$, respectively. The lungs in Figure $13 \mathrm{c}$ show those from a dog struck, nonfatally, in the mid-lateral, right thoracic region with a $0.4 \mathrm{lb}$ missile $2.75 \mathrm{in}$. in diameter travelling at $103 \mathrm{ft} / \mathrm{sec}$. Figure 13d, also from a dog hit in the right lateral thorax with a $0.4 \mathrm{lb}$ missile, demonstrates bilateral hemorrhages 

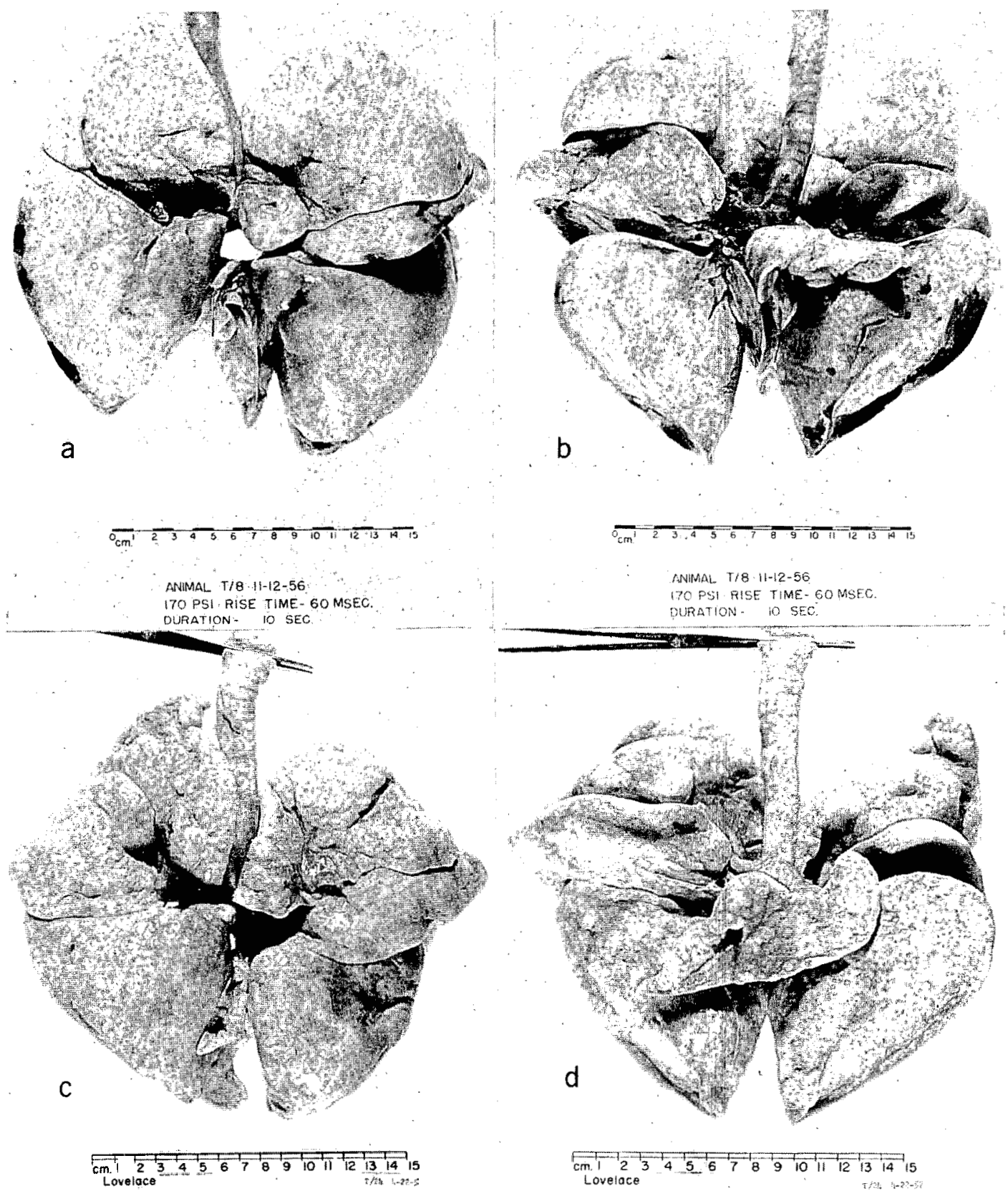

Figure 12. a \& b. Dorsal and ventral views, respectively, of lungs of a dog exposed non-fatally to a shock tube-produced, 10 sec duration overpressure developing in $60 \mathrm{msec}$ to a maximum of $170 \mathrm{psi}$. Note marginal hemorrhagic lesions and absence of generalized areas of damage. $c \& d$. Dorsal and ventral views, respectively, of normal lungs of a dog. 

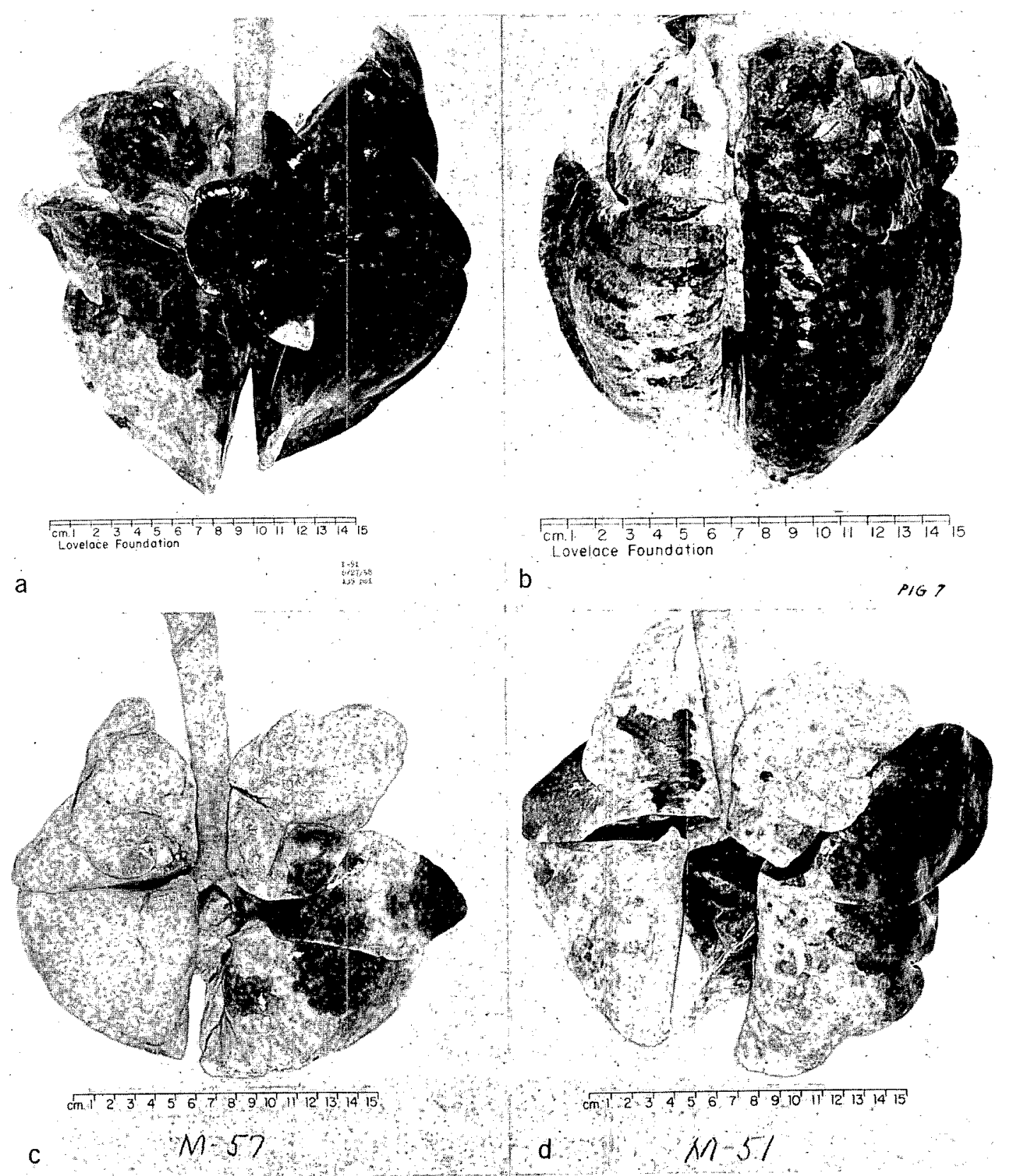

Figure 13. (a) Ventral view of lungs of a dog fatally injured in a shock tube by a 6 to 8 sec duration, reflected overpressure of 44 psi which developed almost instantaneously. Note massive areas of hemorrhage. The $135 \mathrm{psi}$ figure noted in the illustration refers to the diaphragm pressure of the shock tube and not the exposure pressure in the test cell. (b) Dorsal view of lungs of pig fatally injured at the Nevada Test Site by nuclear-produced blast. Overpressures were not measured at the location of exposure at the bottom of a stairway leading to an underground shelter. Note the rib markings, massive hemorrhages and atelectasis of the left upper lobes. (c) Dorsal view of lungs of a dog surviving impact of a 0.4-lb missile travelling 103 $\mathrm{ft} / \mathrm{sec}$. Note the isolated, somewhat discrete, unilateral areas of hemorrhage which occurred on the side of impact. (d) Dorsal view of lung of a dog fatally injured by impact of a $0.4-1 b$ missile travelling $207 \mathrm{ft} / \mathrm{sec}$. Note bilateral location of the hemorrhage most severe on the side of impact. Data courtesy V.C.Goldizen (42). 
found at necropsy after death which occurred in a few minutes following missile impact. In such severely injured animals there appear electrocardiographic signs of hypoxia, and death from cardiac fibrillation has occurred (58). While we feel the lesions have an etiology similar to those noted in air blast, we have not yet succeeded in demonstrating direct, clear-cut instances of air emboli perhaps because (a) the series is at yet small (11 deaths in 47 animals subjected to nonpenetrating missile impact); (b) lung damage in mortally injured dogs is of a less severe type than in blast and possibly precludes massive air emboli from broncho- and alveolar-venous fistulas as presumed in air blast, or (c) air emboli do not occur, which if proven true, will eliminate one plausible explanation for the cause of death from missile impact. Of course, failure to visualize air emboli does not disprove their existence, but the fact remains that the reason for fatality remains obscure.

\section{Notes on Symptoms and Treatment}

Attempts to compare the available observations from animals exposed fatally and non-fatally to blast overpressures with human, primary, air-blast experience proves an interesting if somewhat frustrating experience. The latter to some extent stems from three facts. First, follow-up observations of a significant number of animals non-fatally injured by blast have not been extended routinely over more than a few hours. Second, for all practical purposes, observations on human blast damage begins hours after the injury because the majority of those critically injured die in a matter of minutes and are consequently not at hand for study or early careful examination. Third, available human material is commonly complicated by trauma from debris and displacement and it is difficult, if not impossible, to separate the signs and symptoms due to overpressures per se. However, the basic experiments on animals and observations on man fortunately do not pose any serious inconsistencies and it is possible to piece together a somewhat simple picture from the clinical point of view, which, though not very precise, is satisfyingly sensible considering the available data. A few remarks in this regard will now be presented.

Prophylaxis

Initially, it is well to point out as has King and Curtis (59) that prevention should be practiced whenever possible; e.g., such things as abutments; 
shelters; measures to reduce the rate of pressure rise, sharp pressure reflections, missile production and their impact with a biological target, displace ment and subsequent violent deceleration; and the use of energy-absorbing garments covering the chest and trunk. The stimulus for initiating all possible measures as a routine part of preventive medicine stems from the nature of the primary blast injury, which can produce, as noted previously, immediate death and fatality within 15 to 20 minutes in critically injured animals.

\section{Position}

Any symptomatic human case in which exposure to blast is suspected - particularly with ruptured tympanic membranes, or if, without other external signs of injury, bloody foam and frank blood are observed running from the nose and mouth - should be placed immediately in the left lateral or midway between the prone and left lateral position with the head lowered and kept there for several hours. This is the position of choice to minimize the effects of intravascular air emboli by attempting to avoid migration of air into the coronary and cerebral vessels (50). The head-down position will also aid drainage of the pulmonary airways. However, mechanical suction in appropriate instances should be used aggressively, along with detergent aerosol inhalations in stubborn cases, for the presence of foamy fluids in the trachial and bronchial passages seriously impedes air exchange. If later on, signs of increased venous pressure develop, slight elevation of the head and upper trunk may be helpful (53).

$\underline{\text { Rest }}$

Complete rest is mandatory for it is essential to reduce the work load on the embarrassed heart, lungs and circulation to avoid further pulmonary hemorrhage and edema and heart failure. There exists the possibility of dislodging blood clots "sealing" damaged vessels and broncho- or alveolarvenous fistulas, an event to be avoided at all costs. Reoccurrence of bleeding into the lung has been observed up to five days after exposure (53) and has accompanied other signs in delayed fatalities. There can be little doubt but that blast injuries should be moved no more than is absolutely necessary even when this involves a journey from one hospital to another. 
Pressurization

The use of therapeutic pressurization of the whole body up to 4 to 6 atmospheres, effective in experimental air embolism and suggested as a means of human therapy in blast, would have to be used almost immediately to be of help in the majority of critical injuries. Consequently, such therapy is most often only of academic interest. However, the fact that Clemedson was able to reduce the mortality in fatally blasted rabbits from 100 to 54 per cent by prompt recompression, along with the fact that an occasional animal will not succumb before between 15 and 60 minutes (16), suggests it might be useful to have a pressurization tank available in critical industries and locations; e.g., powder plants, weapon assembly areas, seaports handling explosives, etc. Parenthetically, a medical center processing a large number of chest cases with the inevitable practice of pneumothorax and other procedures involving thoracentesis might well save an occasional case of arterial air embolism. Pressurization not only can be effective because of reduction in the size of gaseous emboli, but also because it can increase the diffusion gradient of oxygen, which may be, but not always, desirable in blast injury as will be noted below under oxygen therapy. Of course, the usual precautions, so well described in the diving and submarine medicine literature, should be rigidly followed to avoid untoward consequences that can arise in pressurization therapy.

Any the rapy involving intrapulmonary application of inspiratory positive pressure is contraindicated.

Analgesics, sedatives and narcotics

Patients subjected to blast may exhibit various levels of awareness from normal mental alertness through amnesias to frank unconsciousness. Also, there can be various grades of motor activity from lethargy through flacid and spastic paralysis to violent convulsions. Too, pain can be present and severe, though early chest pain is frequently absent in mild, but is common and often marked in severe injuries. Whatever the signs, care in the use of narcotics, sedatives, and analgesics must be exercised. In blast injury involving damage to the lungs and heart, coughing and increased motor activity must be controlled for certain for the first few hours and for days if 
necessary, since frank bleeding may continue for $48 \mathrm{hrs}(60)$ and periodic hemoptysis for as long as 7 to 10 days has been reported. Morphine and atropine or othe $r$ narcotics are recommended if necessary to control pain, secretions and restlessness providing less potent measures are ineffective. By way of emphasizing the need for keeping the patient quiet and avoiding the possible reoccurrence of air emboli from the damaged lungs, it is significant that ischemic disturbances of the myocardium can be induced by an injection of as little as $0.025 \mathrm{cc}$ of air directly into the anterior descending branch of the left coronary artery of a dog and that death has followed the injection of $0.05 \mathrm{cc}(50)$.

The problem concerns the necessity of providing rest and at the same time avoiding the undesirability of masking signs of: (a) existing or progressive damage to the central nervous system (head trauma is often involved also), (b) the development of persistent pain in the chest which may aid the diagnosis of early cardiac infarction*, and (c) abdominal injury requiring surgical intervention. The last is important, for though abdominal pain and rigidity a re commonly seen clinically in air-blast injuries and the need for intervention is rare, there nevertheless are cases in which early surgery constitutes a life saving measure. Too, experience indicates abdominal injury, often with rupture of the abdominal organs, is relatively frequent in cases exposed to underwater compared with those subjected to air blast. However, all surgical procedures should be avoided whenever possible for at least $24 \mathrm{hrs}$ because of the poor early tolerance to general anesthesia exhibited by victims of blast (2).

\section{Oxygen the rapy}

Oxygen the rapy has been recommended widely in blast casualties $(2,16,48,53,59)$, and has been reported to be effective in air embolism $(61$, 62). The elimination of any increase in pulmonary vascular resistance due

* Se rum transaminase determinations have not been reported in blast victims or in related animal experiments. However, such estimations might be of great help in detecting early necrosis and infarction of the myocardium whether this be due to the sequellae of trauma, hemorrhage or air emboli. 
to hypoxia is most desirable, but a note of caution is indicated because in animals untoward effects have been observed probably due to pulmonary vas cular dilatation that can be a factor in maintaining or re-initiating hemorrhage (16). Even so, careful employment of oxygen in all patients with (1) cyanosisor hypoxia in those cases with low hemoglobin from hemorrhage which sometimes precludes the development of cyanosis, (2) persistent chest pain and electrocardiographic anomolies, and (3) in selected cases with signs of centra1 nervous system damage, no doubt is indicated. However, careful control, involving use of reduced concentrations in some cases and discontinuance if any signs of recurrence of pulmonary hemorrhage develop, should be maintained. When available and when the indications for oxygen therapy exist, the use of helium-oxygen mixtures to reduce the work of breathing certainly is the procedure of choice.

Intravenous medications and digitilization

Because of damage to the thoracic organs, a lowered blood pres sure almost always accompanies severe blast injury. This may be confused with the ordinary shock syndrome often accompanying trauma when in reality the low systemic blood pressure stems from (a) a myocardium insulted by bruising, hemorrhage and insufficiencies of the circulation which are sequellae of non-fatal air embolism; (b) pulmonary emphysema, hemorrhage and edema serving to increase the work load on the right heart and interfere with efficient oxygenation of the blood; and (c) reflex lowering of the peripheral blood pressure initiated through the vagal endings situated in the damaged lungs, which is interpreted to be a protective mechanism serving to minimize the work load of the left heart (3). Such events contraindicate the use of intravenous fluids, plasma or blood unless absolutely necessary because of hemorrhage from lacerations or other wounds or because the systemic pressure falls to definitely dangerous levels. Even when required, intravenous fluids must be used with caution, for there is danger of overloading an already damaged heart and pulmonary circulation, and often difficulties with electrolyte balace occur due to malfunction of the renal system since damage to the kidneys is not uncommon in blast cases (8).

With fluids more commonly, or even without intravenous medication, 
acute heart failure with marked pulmonary edema can develop suddenly in blast cases (53). Instances of fulminating cardiac insufficiency have been described as long as five days after injury and some cases show an elevated venous pressure for which venisection and cardiac glocosides have been employed effectively (53). The use of intravenous digitalization in such instances is strongly indicated and can prove life saving. Though digitalization has been recommended $(2,53)$ for the true cardiac insufficiency which is one of the fundamental consequences of blast injury, instances of its use are all too sparse in the literature. In fact, a blast injury requiring intravenous fluids to control a low blood pressure probably should be cautiously digitalized simply on principle.

Caffeine administered systemically at first in large doses as a cardiac stimulant and diuretic and later by mouth in coffee has proven useful in treating blast casualties providing the dose in the late afternoon and evening is cut back so as not to interfere with sleep which is commonly disturbed in such cases (2).

Intravenous alcohol slowly injected as a 30 per cent solution in doses up to 30 to $40 \mathrm{cc}$ has been recommended for its euphoric and mild anathetic effects. Alcohol also acts as diuretic and a dilator of the coronary and peripheral vessels, all additional desirable effects. Though papaverine as a vasodilator is considered inappropriate because of secondary hemorrhages of the lungs, no such difficulties have been reported with alcohol and cessation of blast-produced pulmonary hemorrhage in a few hours has been described though the sputum remained rusty brown for several days (2). Even so, the therapist should be alert, as with oxygen, to the possibility that the vasodilating properties of alcohol may have untoward effects on the pulmonary vascular bed.

\section{Pneumothorax, thoracentesis and antibiotics}

In view of the fact that pneumothorax can occur from primary blast injury (9) probably from the rupture of not uncommonly seen pleural blebs (4), it is interesting that the rapeutic pneumothorax has been suggested (63) as a "last-ditch" (2) measure to control continued pulmonary hemorrhage in stubborn cases that have not responded even to coagulants that should, of 
course, be employed (2). Pneumothorax can be dangerous and should be used with extreme caution and only in shrewdly selected, desperate cases.

Careful evaluation of the chest signs evident by $x$-ray, which by itself is not always definitive, and by physical examination is essential. Fullness of the chest, particularly the lower half (64), coarse or fine rales, rhonchii, areas of diminished or absent breath sounds, unequal expansion, decreased movements or elevation of the diaphragm, consolidation, dullness, hyperresonance and an enlarged heart, particularly on the right, may all occur. It is of importance to screen those cases with pleural effusions (with or without hemothorax), pneumothorax, consolidations and cardiac enlargement.

Thorancentesis to remove pleural fluid may be most helpful in patients with markedly embarrassed pulmonary exchange, but should be performed early only in case of dire necessity to avoid possible resumption of hemorrhage that might accompany expansion of the lung. For this reason, even delayed thorancentesis should be approached and accomplished cautiously.

Apparent enlargement of the heart may occur because of increased pulmonary pressure, impending or existing heart failure, because of pericardial effusions (65) and early or delayed hemorrhage into the pericardium (66). In the case of actual or threatened heart failure with elevated venous pressure, rapid digitilization and venisection should be considered. Enlargement due to fluid, however, can progress to tamponade and decompression of the pericardial sac is indicated.

Consolidations - scattered, irregular, isolated or confluent - may be seen in blast victims and often resemble those noted in broncho or lobar pneumonia by $x$-ray and physical examination. Without complication these blast-produced areas of hemorrhage clear remarkably well in man and animals. However, infections in the human case have been reported as frequent complications (67) and when present should be treated as any pneumonitis. Too, prophylactic use of antibiotics deserves consideration in all severe cases in an attempt to prevent any additional load on an already damaged heart and pulmonary circulation. Also, all cases with pneumothorax or with hemothorax arising from rupture of the surface of the lung are potentially contaminated and anti- 
biotics should be employed routinely to avoid development of empyema. Anesthesia

The poor tolerance of blast cases to general anesthesia has been mentioned previously and is noted again for emphasis. There is ample evidence that great care and clinical judgement is required to avoid all possible surgery for at least 24 to $48 \mathrm{hrs}(2,53,59,67,68)$, and in some instances longer, because the experience of the British workers during the second World War $(68,69)$ taught them to regard blast damage to the lung as a progressive lesion. As has been stated above, capillary bleeding in the lung was documented over periods of several days and such observations stimulated the practice of avoiding general anesthetics until it was shown that the lung lesions had stabilized (69). Employment of other than general anesthetics in blast injuries with pulmonary and cardiac involvement requiring early surgery, of course, deserves the strongest consideration.

One clinical observation noted in blast casualties by Roberts (69) deserves mention as a guide to surgeons and anesthesiologists. Some blast cases showed minute punctiform hemorrhages in the skin of the abdomen and chest which were not readily apparent. When observed it was assumed that the patient was suffering from blast until the contrary was proved.

In this regard, the classical pathognomonic signs of air embolism might also be helpful to the clinician pre and post mortem. These are:

(1) Ophthalmoscopic detection of air embolism directly and immediately in the retinal vessels as streaming bubbles or pale silvery sections representing columns of air, or indirectly and later as pallor of the retina which may be noted for several days and be associated with diminution of visual acuity $(70-74)$.

(2) Liebermeister's sign consisting of sharply defined a reas of pallor in the tongue depending upon the lingual arteries or their branches involved in air embolism (75).

(3) Marbling of the skin, a dermal manifestation due to embolism of the skin vessels especially over those portions 
of the body superiorly located at the time emboli occurred (50).

(4) "Air-bleeding" that has been observed from skin incisions made over the most superior portions of the body (49).

(5) Roentgenologic demonstration of aix in the cerebral vessels of little value except as a means of post mortem diagnosis (51).

\section{General}

The multiple nature of blast-produced damage from overpressure, flying debris and injuries as a consequence of displacement is amply illus trated by war casualty experiences (75) and by medical reports of the Texas City Disaster $(8,76,77)$. The free use of heat, fluids, plasma, blood and vasopressors to control traumatic and hemorrhagic shock, along with the requirements for emergency surgery, can be ruled paramount in the majority of such cases. However, among the secondary and tertiary blast casualties will be those who have survived the immediate hazards, but who will exhibit various degrees of primary blast injuries to the thoracic and abdominal organs. It is these that pose a problem to the medical profession in diagnosis, treatment and careful follow-on care.

While it is unfortunate that the pathophysiologic nature of primary blast damage portends early fatality for many individuals exposed to higher overpressures, both incident and reflected, it is at the same time fortunate that the hazards from overpressure do not extend farther from an explosion than they do, being outranked in this regard by both the dangers of missile impact and displacement as will be noted later. Even so, the properly informed and alert practitioner today is in a much more favorable position than in the past because the understanding of the basic lesions due to overpressure is currently more advanced. Certainly in the future, cases which previously would have been lost early, will survive because of a more enlightened and sophisticated approach to therapy. 
With time will come not only a more lucid understanding of the immediate events now somewhat obscure but a true appreciation of the sequellae of primary blast damage. A case in point concerns the cause of the post-exposure hypertension reported in surviving victims of the Texas City disaster $(76,77)$. Another involves documentation in animals and man , of the post-concussive status of the respiratory and cardiovascular system damaged by hemorrhage, edema, traumatic emphysema, interstitial and arterial air embolism. Appreciation of the potential dangers of pulmonary emphysema prompted Desaga (2) to suggest that breathing exercises should be of use in some blast cases. Too, the true meaning and consequences of the perivenous hemorrhagic areas of the brain and other body tissues following arterial air embolism (51) no doubt will be elucidated by farther research. Such events might well increase the peripheral resistance temporarily, if not permanently, in some instances and be at least one factor in the "blast hypertension" mentioned above.

\section{RELATION TO NUCLEAR EXPLOSIONS}

It is important that investigative work in the blast field continue, for the nuclear age which dawned in 1945, has progressively spawned nuclear explosives of larger and larger yields. That such exist must be faced squarely, for no one can state with certainty that there will be sometime in the future neither a nuclear war nor an accidental detonation of a nuclear device. In either eventuality, the medical profession will face a task for which it is poorly prepared at the present time. Such thinking has prompted the inclusion here of a final brief section which may serve - to some degree at least - to illustrate the magnitude of the nuclear blast problem and in a small way define somewhat the challenge to the medical profession.

\section{Major Hazards from Nuclear Explosions}

Initially, it is well to point out that blast effects comprise only one of the major hazards of modern explosives, which in the nuclear case includes in addition, dangers from thermal radiation and fire storm, initial ionizing radiation and residual ionizing radiation (79): The last mostly concerns the fallout problem (79). Table 10 was prepared using data for the typical air burst from The Effects of Nuclear Weapons (79) to illustrate the range and 
Table 10. The Ranges and Areas for Three Major Effects Arising from Typical Air Nuclear Explosions for Indicated Yields

\begin{tabular}{|c|c|c|c|c|c|c|c|c|c|c|}
\hline \multirow{3}{*}{$\begin{array}{l}\text { Major } \\
\text { effect }\end{array}$} & \multicolumn{10}{|c|}{ Range and areas for indicated yields* } \\
\hline & \multicolumn{2}{|c|}{$20 \mathrm{KT}$} & \multicolumn{2}{|c|}{$100 \mathrm{KT}$} & \multicolumn{2}{|c|}{$1 \mathrm{MT}$} & \multicolumn{2}{|c|}{$10 \mathrm{MT}$} & \multicolumn{2}{|c|}{$20 \mathrm{MT}$} \\
\hline & $\mathrm{mi}$ & $\mathrm{mi}^{2}$ & $\mathrm{mi}$ & $\mathrm{mi}^{2}$ & $\mathrm{mi}$ & $\mathrm{mi}^{2}$ & $\mathrm{mi}$ & $\mathrm{mi}^{2}$ & $\mathrm{mi}$ & $\mathrm{mi}^{2}$ \\
\hline \multicolumn{11}{|l|}{$\begin{array}{l}\text { Initial } \\
\quad \text { Radiation }\end{array}$} \\
\hline $30 \mathrm{rem} * *$ & 1.18 & 4.37 & 1.51 & 7.16 & 2.07 & 13.5 & 2.91 & 26.6 & 3.30 & 34.2 \\
\hline $100 \mathrm{rem}$ & 0.99 & 3.08 & 1.29 & 5.23 & 1.81 & 10.3 & 2.55 & 20.4 & 2.88 & 26.1 \\
\hline \multicolumn{11}{|l|}{ Blast } \\
\hline $1 \mathrm{psi}^{+}$ & 2.71 & 23.1 & 4.64 & 67.6 & 10.0 & 314 & 21.5 & 1450 & 27.1 & 2310 \\
\hline $5 \mathrm{psi}$ & 1.06 & 3.53 & 1.81 & 10.3 & 3.90 & 47.8 & 8.40 & 222 & 10.6 & 353 \\
\hline \multicolumn{11}{|l|}{$\begin{array}{l}\text { Thermal } \\
\text { Burns }\end{array}$} \\
\hline 1st degree & 2.47 & 19.2 & 4.97 & 77.6 & 13.3 & 556 & 360 & 4070 & 49.2 & 7600 \\
\hline 2nd degree & 1.72 & 9.29 & 3.40 & 36.3 & 9.0 & 254 & 23.8 & 1780 & 31.9 & 3200 \\
\hline
\end{tabular}

*1 kiloton (KT) equivalent in explosive yield to 1,000 tons TNT 1 megaton $(\mathrm{MT})=1,000 \mathrm{KT}$

**em = a biologically effective dose unit of ionizing radiation (roentgen equivalent man)

tpsi = pounds per square inch

++1 st degree burn roughly equivalent to a severe sunburn

2nd degree burn considered as a burn severe enough to blister

Burns refer to the uncovered white human skin

Data from Glasstone (79) 
areas which might be involved from the major effects following the detonation of a nuclear explosive yielding $20 \mathrm{KT}, 1,000 \mathrm{KT}(1 \mathrm{MT}), 10 \mathrm{MT}$ and $20 \mathrm{MT}$ $(80)$.

In studying the table the reader should keep the following facts in mind $(80,81)$ :

(1) The typical air burst does not involve any immediate hazard from residual radiation.

(2) The two nuclear explosions in Japan were approximately $20 \mathrm{KT}$ each.

(3) The square miles destroyed were estimated at 4.5 and 1.8 for Hiroshima and Nagasaki, respectively.

(4) Casualty estimates involved 110,000 injured and 106, 000 killed and missing from a combined population of 450,000 for the two Japanese cities.

(5) Among Japanese survivors, blast damage accounted for 70 per cent of the casualties while burns were implicated in 65 to 85 per cent.

(6) A 30 rem dose of ionizing radiation will temporarily alter the blbod count of most individuals.

(7) The beginning sickness dose of ionizing radiation has a threshold near 100 rem.

(8) Ordinary residences will be completely destroyed by 5 psi from "small" and 4 psi from "large" explosive yields.

(9) One psi will easily remove all windows and most doors from buildings.

(10) Thermal fluxes required for igniting fine kindling fuels are about equal to those which will produce second degree burns.

Table 10, considered along with the 10 points set forth above, needs little emphasis, but it is doubtful that the average physician - not to mention the population at large - realizes the casualty potential of modern weapons. To 
consider the experience at Hiroshima alone, casualties were near 140,000, about half of whom were killed and missing $(79,80)$. The radius to the 5 psi line for a $20 \mathrm{KT}$ "typical" air burst is about $1.1 \mathrm{mi}$ and encloses an area near $3.5 \mathrm{sq} \mathrm{mi}$. A $20 \mathrm{MT}$ explosion is 1,000 times as large, but the radius to the $5 \mathrm{psi}$ line is only 10 -fold that for the $20 \mathrm{KT}$ or about $11 \mathrm{mi}$, while the area involved is 100 -fold that for the $20 \mathrm{KT}$ or about $350 \mathrm{sq} \mathrm{mi}$. This means that were such an area in any city having an equal population density* subjected to a $20 \mathrm{MT}$ explosion, casualties would be of the order of $100 \times 140,000$ or $14,000,000,7,000,000$ of whom would be killed and missing. Even if one assumed half the population density and an additional decrease in exposure by one-half due to shielding from stronger and heavier buildings, the estimate would only drop by a factor of $\frac{14}{4}$ or to $3,500,000$, with 1,750,000 numbered as dead and missing.

Such numbers comprise an impossible load on unprepared medical personnel and facilities anywhere in the world, and certainly would swamp the planned efforts of the best trained and disciplined group that can be visualized. Obviously, the answer - and there is one - concerns prevention (minimization) of casualties. It makes sound sense to suggest that the medical profession should insist upon, and be given the support necessary to practice blast, radiation and thermal prophylaxis, for this offers the only possible way of reducing casualties to manageable levels.

\section{Prediction of Potential Casualties from Blast}

To pass on to remarks more directly related with the hazard estimates from primary, secondary and tertiary blast, Figures 14-17, inclusive, prepared from data included in a recent study by one of us (14), are presented for study. These charts apply only to 1 and $10 \mathrm{MT}$ nuclear explosions detonated on the earth's surface at sea level and consequently underestimate the situation for the air burst. The figures do not deal with effects from either ionizing or thermal radiation. Rather, they set forth best tentative estimates for the ranges over which, and the areas inside which, potential human casualties from nuclear-produced blast can be expected from overpressure, missiles

*Hiroshima population density was $35,000 / \mathrm{sq} \mathrm{mi}(79,80)$. 


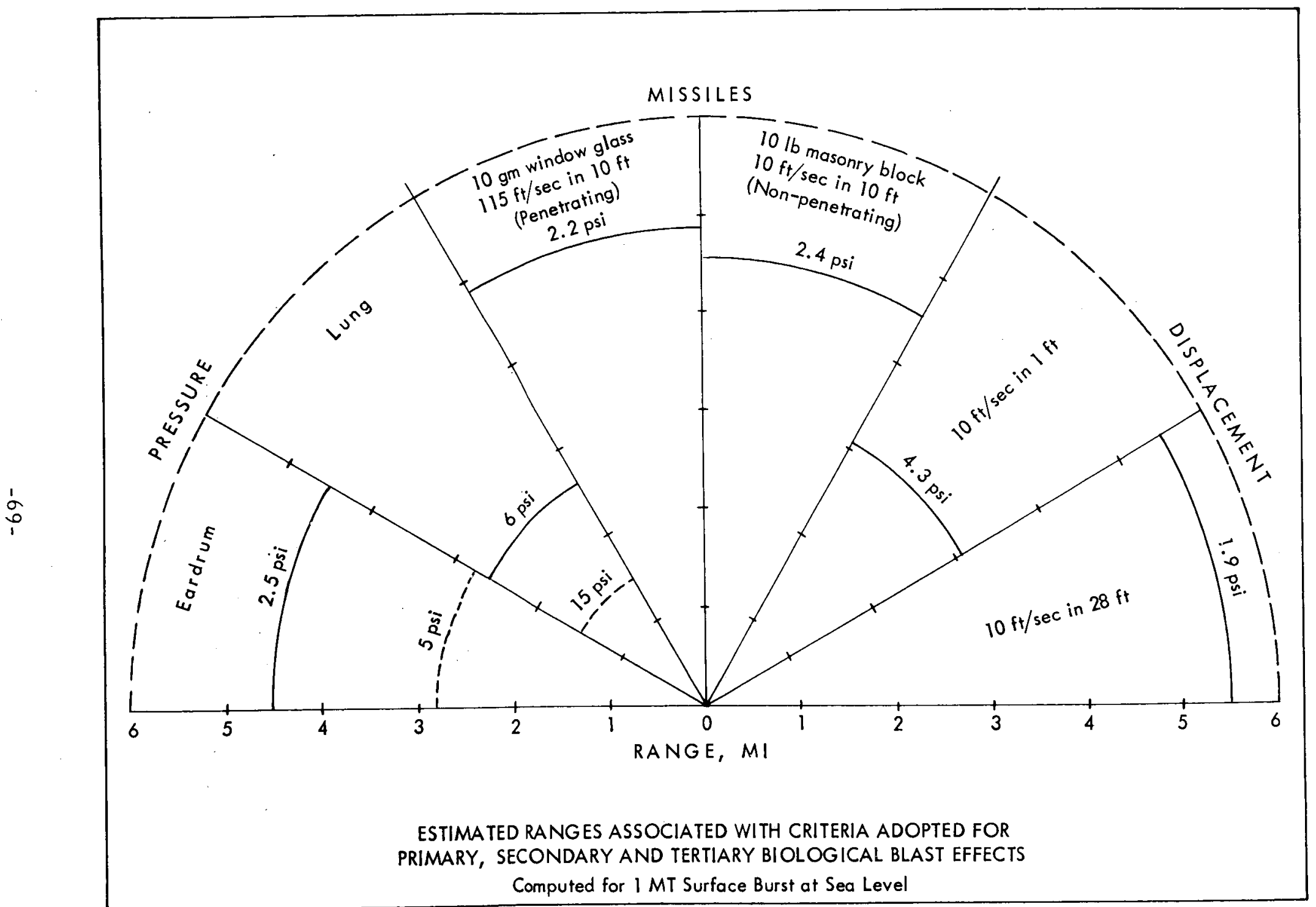

Figure 14. The estimated ranges for a $1 \mathrm{MT}$ surface explosion corresponding to tentative criteria defining the threshold for potential blast casualties from overpressure, missiles and displacement. Data computed by I. G. Bowen (42). 


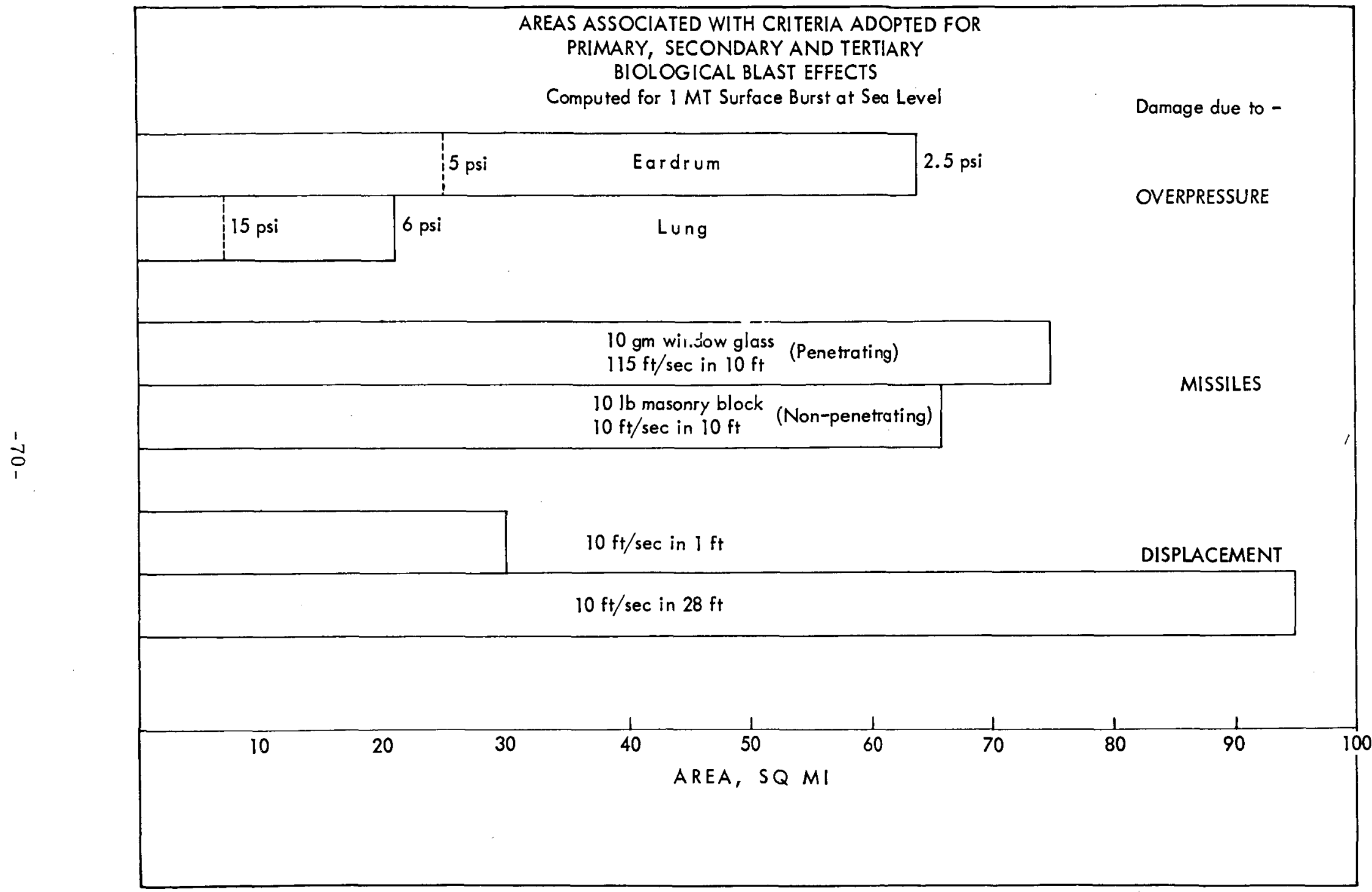

Figure 15. The estimated areas for a $1 \mathrm{MT}$ surface explosion over which potential

blast casualties can be expected from overpressure, missiles and displacement.

Data computed by I. G. Bowen (42). 


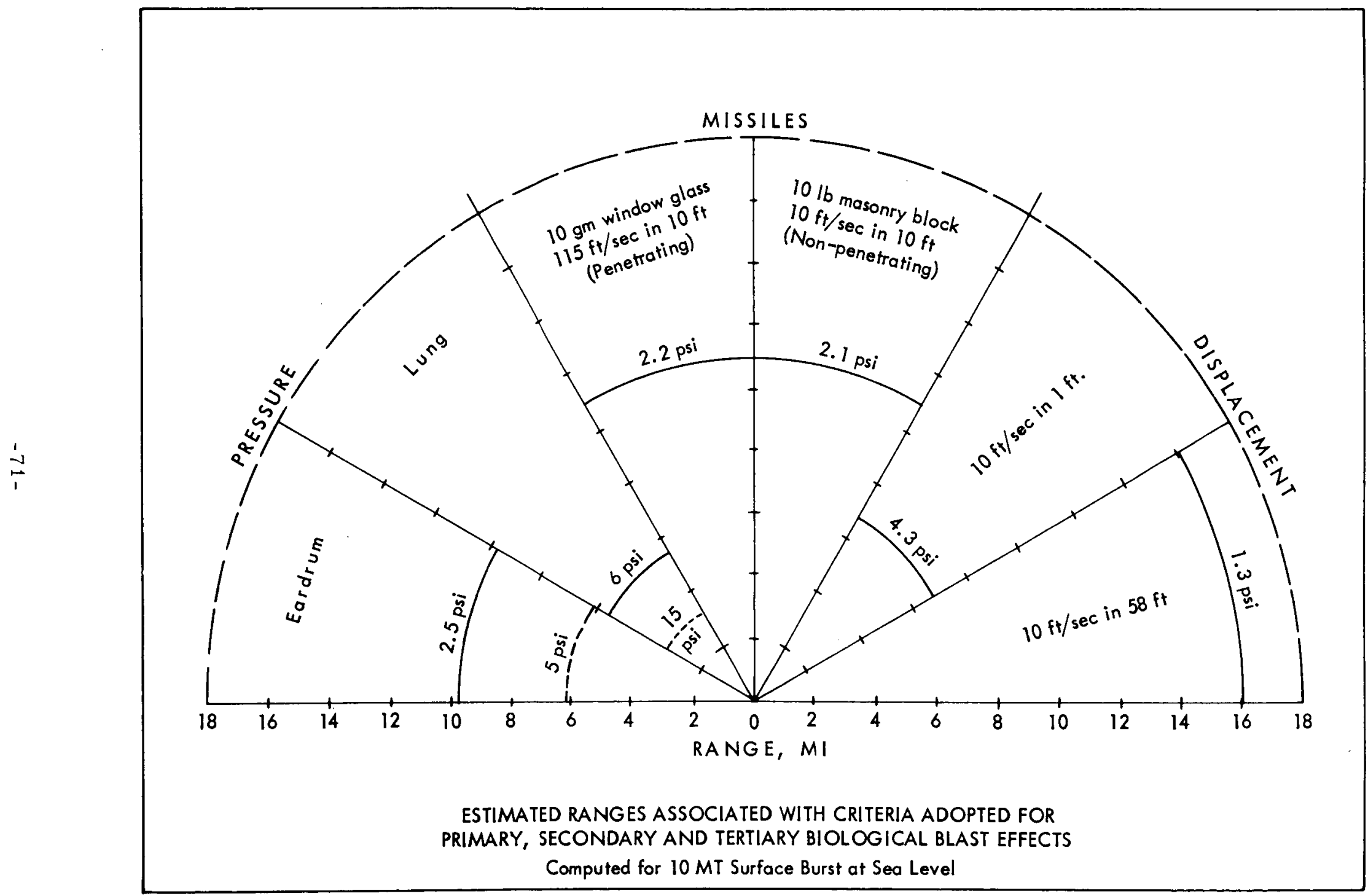

Figure 16. The estimated ranges for a $10 \mathrm{MT}$ surface explosion corresponding to tentative criteria defining the threshold for potential blast casualties from overpressure, missiles and displacement. Data computed by I. G. Bowen (42). 


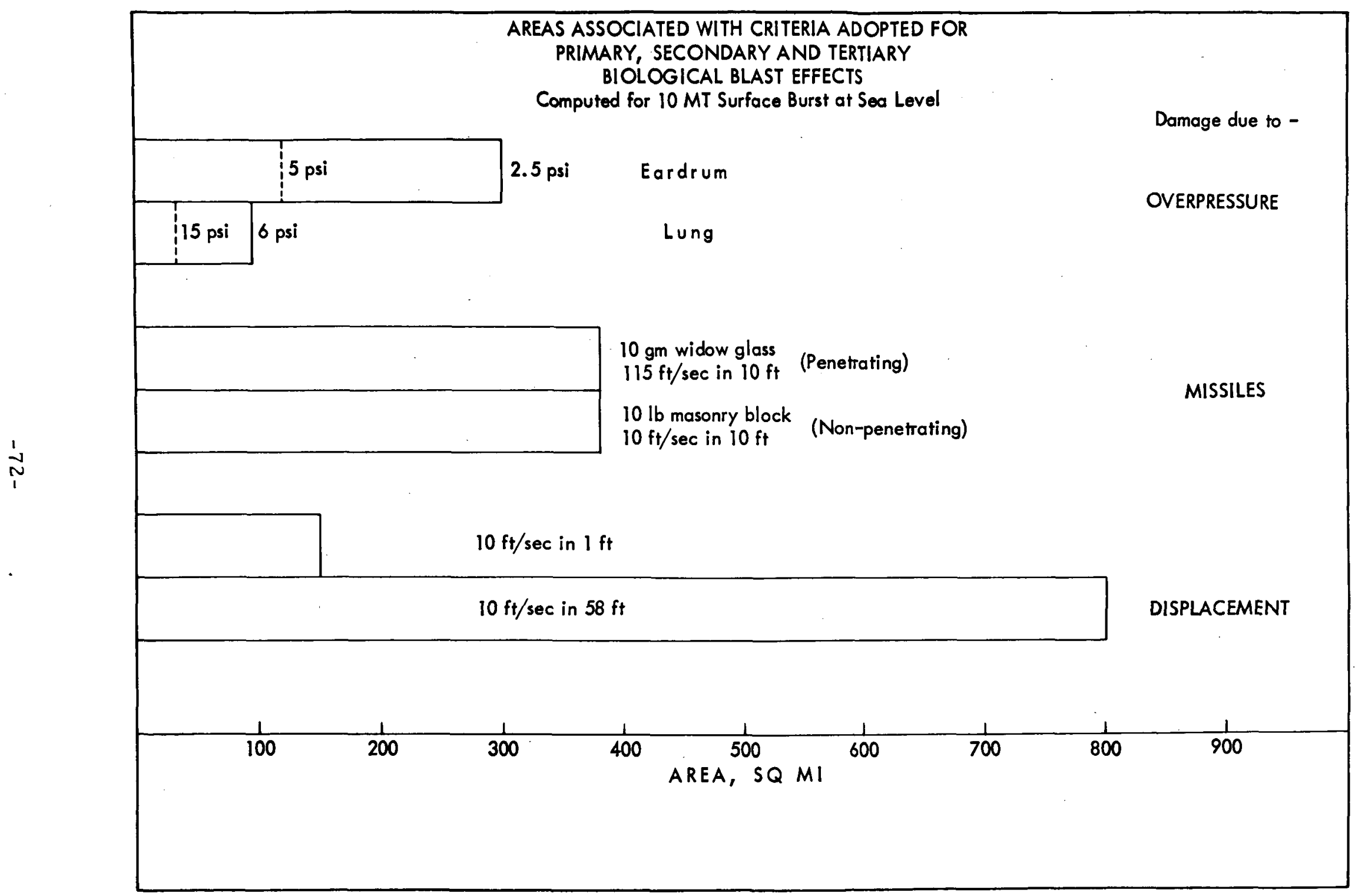

Figure 17. The estimated areas for a $10 \mathrm{MT}$ surface explosion over which potential blast casualties can be expected from overpressure, missiles and displacement.

Data computed by I. G. Bowen (42). 
and displacement. Only a few elementary concepts and simple as sumptions are needed to interpret the figures.

\section{Criteria for Casualty Assessment}

First, the estimates employed what can be called "free-field" weapons effect data, meaning those bomb-produced changes in the environment which can be expected in the absence of buildings or other structures that might provide shielding. Thus, the estimates can only be crude and tentative since it is impossible at the present time to compute and set forth what the hazards might be at the locations of biological targets; e.g., inside a variety of typical structures such as houses, apartments, office buildings, factories, etc. (14).

Second, casualties were defined simply as any individual injured sufficiently to be incapable of self-care and hence a burden to someone else (14).

Third, it was considered desirable to attempt to fix the range at which casualties would just begin for each blast hazard; e.g., the range outside of which there would be no or only a few casualties, and inside of which casualties would progressively increase and injuries would become progressively more severe (14).

Fourth, to accomplish this it was necessary to fix, a rbitrarily, criteria for bringing together the physical and human biological parameters involved. The criteria adopted, and presented in outline form below, were:

\section{a. Biological}

1. Primary blast (overpressure)

(a) Tympanic membrane. The threshold for rupture of the tympanic membrane was set at 5 psi max-incident or reflected overpressure $(9,14,29,30,44,81-83)$.

(b) Thoracic organs. The threshold for pulmonary hemorrhage in humans for "fast"-rising, "long"-duration overpressures was fixed at 15 psi max-incident or reflected overpressure $(14,15,32)$.

2. Secondary blast effects (missiles)

(a) Skull fracture and concussion. An impact velocity 
of $10 \mathrm{ft} / \mathrm{sec}$ or below for a fairly smooth, 10-1b missile (average weight of human head) was considered unlikely to cause serious head injury $(14,15,19,84-86)$.

(b) Penetration of body wall. Since it is known that a $10 \mathrm{gm}$ glass fragment travelling at $115 \mathrm{ft} / \mathrm{sec}$ has only a 1 per cent probability of penetrating the abdominal wall of a dog and reaching the peritoneal cavity (11), it was assumed that missiles of this material, weight, and velocity would not seriously injure a significant number of clothed human subjects.

\section{Tertiary blast effects (displacement)}

Based on available data regarding the impact velocities required to produce experimental skull fracture and failure of the bones of the ankles and feet $(14,15,19,84-87)$, $10 \mathrm{ft} / \mathrm{sec}$ and below was adopted as the velocity under which decelerative impact with hard, flat surfaces would be unlikely to comprise a hazard to humans. Also, this assumption is consistent with animal studies of mortality from dynamic decelerative impact (42).

\section{b. Physical}

1. Primary blast (overpressure)

From known relations between incident and reflected pressures, the 6 and 15 psi criteria mentioned above may arise from 2.5 and 6 psi incident overpressure, respectively, in a geometry conducive to maximal pressure reflection 12 , $14,15,79,80)$. "Free-field" scaling of the overpressures was accomplished by conventional computations for the 1 and $10 \mathrm{MT}$ explosive yields $(79,80)$. 
2. Secondary blast (missiles)

Empirical data concerning measured missile veloccities determined at full-scale nuclear tests and laboratory work has allowed formulation of a computational approach to predicting missile velocities $(10,11,13-15$, 88). Because missile velocity, among other things, is determined by the distance a missile is impelled by the blast shock and winds (10), $10 \mathrm{ft}$ of travel was arbitrarily chosen, and the range prediction as a function of weapon yield, was accomplished by methods now routine (88) for:

(a) the $10 \mathrm{gm}$ glass fragment to reach a velocity of 115 $\mathrm{ft} / \mathrm{sec}$ in $10 \mathrm{ft}$ of travel (penetrating missile criteria), and (b) the 10-lb masonry missile to reach a velocity of $10 \mathrm{ft} /$ sec in $10 \mathrm{ft}$ of travel (nonpenetrating missile criteria).

3. Tertiary blast (displacement)

Empirical data are available for anthropometric dummies displaced by nuclear blast (18) and it has been found possible, using the mathematical model for missiles, to treat man as a missile $(14,15,88)$ and approximate the range-yield relationships for a $160-1 b \operatorname{man}(a)$ to reach a velocity of $10 \mathrm{ft} / \mathrm{sec}$ in $1 \mathrm{ft}$ of travel, and (b) to reach a velocity of $10 \mathrm{ft} / \mathrm{sec}$ when no restriction was placed upon the distance of travel. The latter actually defines the lowest overpressure and the greatest distance of travel possible for the weapon yields considered here $(1$ and 10 MT).

\section{Casualty Potential of High Yield Nuclear Explosions}

Such a simplified approach to the assessment of the threshold effects for biological blast damage has allowed tentative approximations of the critical range for different yield weapons at and beyond which a significant number of blast casualties are not anticipated, but inside of which the incidence of such casualties would progressively increase from near zero to very high numbers 
with decreasing range; e.g., the critical range represents that range at which blast is an acceptable hazard in an emergency from nuclear explosions. To date no attempt has been made to make estimates inside the critical range. However, the estimates now available - tentative as they are and as they must be considered - are summarized in graphic form in Figures 14-17.

Figures 14 and 15 apply to the $1 \mathrm{MT}$ surface burst at sea level and show respectively the ranges inside of which, and the areas over which, primary, secondary and tertiary blast effects can be anticipated. In like manner, Figures 16 and 17 present similar data for the $10 \mathrm{MT}$ surface burst at sea level.

From a study of the figures it is apparent that under some circumstances displacement from blast can be the most far-reaching hazard; that overpressure effects extend the least distance from the explosive source and that missile damage is in an intermediate position, but reaches well beyond the range of danger from primary blast and overlaps the displacement hazard, depending upon the distance of travel allowed or available to the displaced biological target.

For a crude assessment of the relative hazards from the different blast effects one can regard eardrum rupture as a relatively minor injury and read average values from Figures 15 and 17 for the 1 and $10 \mathrm{MT}$ yields, respectively. Such a summary is presented in Table 11.

To learn what the data in Table 11 means in terms of potential blast casualties, it is necessary to utilize population density figures which are tabulated by the U.S. Census Bureau. Some typical figures (89) are shown in Table 12. As a comparison, it is interesting to note that the population densities for Hiroshima and Nagasaki in 1945 were 35,000 and 65,000 persons per square mile, respectively $(79,80)$. A glance at the figures in the right column of Table 12, which indicate the rank of the cities by population density, shows that of the 30 cities tabulated, New York, Chicago, San Francisco and Boston have the highest population densities, being respectively, about 25,000, $17,500,17,400$ and 16,800 persons per square mile. The lowest numbers tabulated were for Albuquerque, San Diego, Houston, and New Orleans with round number densities of $3,600,3,400,3,300$, and 2,900 persons per square mile, respectively. 
Table 11. Approximate Areas for Potential Blast Casualties

\begin{tabular}{lcc}
\hline \multirow{2}{*}{ Agent } & Area in sq mi for 1 and $10 \mathrm{MT}$ yields \\
\cline { 2 - 3 } Overpressure & 20 & $10 \mathrm{MT}$ \\
Missiles & 75 & 100 \\
Displacement* & 80 & 480 \\
\hline
\end{tabular}

* The values shown were computed for a 160-1b man "allowed" to reach a velocity of $10 \mathrm{ft} / \mathrm{sec}$ after $10 \mathrm{ft}$ of travel. 
Table 12. Population Density Data for a Sample of U.S. Cities*

\begin{tabular}{|c|c|c|c|c|}
\hline City & Population & $\begin{array}{l}\text { Area } \\
\mathrm{sq} \mathrm{mi}\end{array}$ & $\begin{array}{l}\text { Population } \\
\text { per sq mi }\end{array}$ & $\begin{array}{c}\text { Density } \\
\text { rank }\end{array}$ \\
\hline Albuque rque** & 203,960 & 56 & 3,642 & 27 \\
\hline Baltimore & 949,708 & 78.7 & 12,068 & 12 \\
\hline Birmingham & 362,037 & 65.3 & 5,544 & 23 \\
\hline Boston & 801,444 & 47.8 & 16,767 & 4 \\
\hline Buffalo & 580,132 & 39.4 & 14,724 & 6 \\
\hline Chicago & $3,620,962$ & 207.5 & 17,450 & 2 \\
\hline Cleveland & 914,808 & 75 & 12,197 & 11 \\
\hline Dallas & 434,462 & 112.0 & 3,879 & 26 \\
\hline Denver & 415,786 & 66.8 & 7,721 & 15 \\
\hline Detroit & $1,849,568$ & 139.6 & 13,249 & 8 \\
\hline Galveston & 66,568 & 8.1 & 8,218 & 14 \\
\hline Houston & 596,163 & 160 & 3,260 & 29 \\
\hline Kansas City ${ }^{+}$ & 586,175 & 99.3 & 5,903 & 20 \\
\hline Los Angeles & $1,970,358$ & 450.9 & 4,370 & 25 \\
\hline Minneapolis & 521,718 & 53.8 & 9,697 & 13 \\
\hline Mobile & 129,009 & 25.4 & 5,079 & 24 \\
\hline New Orleans & 570,445 & 199.4 & 2,861 & 30 \\
\hline New York City ${ }^{++}$ & $7,891,957$ & 315.1 & 25,046 & 1 \\
\hline Omaha & 251,117 & 40.7 & 6,170 & 19 \\
\hline Philadelphia & $2,071,605$ & 127.2 & 16,286 & 5 \\
\hline Phoenix & 106,818 & 17.1 & 6,247 & 18 \\
\hline Pittsburg & 676,806 & 54.2 & 12,487 & 10 \\
\hline Portland, Oregon & 373,628 & 64.1 & 5,829 & 22 \\
\hline Saint Louis & 856,796 & 61 & 14,046 & 7 \\
\hline San Antonio & 408,442 & 69.5 & 5,877 & 21 \\
\hline San Diego & 334,387 & 99.4 & 3,364 & 28 \\
\hline San Francisco & 775,357 & 44.6 & 17,385 & 3 \\
\hline Seattle & 467,591 & 70.8 & 6,604 & 17 \\
\hline Tulsa & 182,740 & 26.7 & 6,844 & 16 \\
\hline Wa shington, D.C. & 802,178 & 61.4 & 13,065 & 9 \\
\hline
\end{tabular}

*U.S. 1950 Census figures quoted from ref. (89).

* Data from Albuquerque Chamber of Commerce for estimates 1 July 1959 +Combines Kansas City, Kansas, and Kansas City, Missouri

++ Includes the five boroughs of New York City 
By combining the data in Tables 11 and 12 and using the population density figures for the cities having the four highest and four lowest values, Table 13 was prepared to indicate the order of magnitude of potential casualties to be expected from blast.

A study of Table 13 indicates that many of the numbers predicted for potential casualties are actually larger than the populations of the city involved as given in Table 12. This is a somewhat stunning fact, for it means that the areas covered by some of the blast effects from single large yield explosions are greater than are the "official" areas of even the largest cities. A yet more blunt means of stating the possibilities is: detonate one explosion, exit one city.

It is well to point out here that the estimates set forth in Table 13 are conservative. Consequently, actual casualties from blast can be expected to be much lower than those estimated as potential casualties, for the latter really represent approximations of near the maximum possible number of blast injuries assuming the population density figures applied to the areas set forth for each effect. However, even if one were to reduce the estimates by factors of 2,5 or 10, the numbers of individuals from one single large yield explosion who should have medical care are so large as to confound comprehension. To strain comprehension still more, only requires the addition of one quite realistic statement; namely, the necessity of adding the number of sick and injured that would result from damage associated with thermal radiation, fire storm, initial and residual radiation, recalling of course, that the last, were it of any relative significance, would be associated only with explosions whose fireballs came in contact with the surface of the earth.

\section{Necessity for Casualty Prevention}

The writers are convinced that the problems associated with the advent of nuclear explosions as sketched above are not insurmountable. The picture becomes startlingly encouraging when one imagines the dividend which could accrue from measures:

1. to enhance the survival of medical and paramedical personnel, their equipment and facilities, for care of the maimed and injured requires living, not dead, physicians, nurses and technicians, and 
Table 13. Potential Blast Casualties for a Sample of Eight American Cities from 1 and 10 MT Nuclear Explosions

\begin{tabular}{|c|c|c|c|c|c|c|}
\hline \multirow{3}{*}{ City } & \multicolumn{6}{|c|}{ Potential Blast Casualties from 1 and $10 \mathrm{MT}$ Surface Bursts } \\
\hline & \multicolumn{3}{|c|}{$1 \mathrm{MT}$} & \multicolumn{3}{|c|}{$10 \mathrm{MT}$} \\
\hline & Pressure & Missiles & $\begin{array}{c}\text { Displace- } \\
\text { ment }\end{array}$ & Pressure & Missiles & $\begin{array}{c}\text { Displace- } \\
\text { ment }\end{array}$ \\
\hline New York & 480,920 & $1,803,450$ & $1,923,680$ & $2,504,600$ & $9,137,480$ & $10,820,700$ \\
\hline Chicago & 349,000 & $1,308,750$ & $1,396,000$ & $1,745,000$ & $6,631,000$ & $7,852,500$ \\
\hline San Francisco & 347,700 & $1,303,875$ & $1,390,800$ & $1,738,500$ & $6,606,300$ & $7,823,250$ \\
\hline Boston & 335,340 & $1,257,525$ & $1,341,360$ & $1,676,700$ & $6,371,460$ & $7,545,150$ \\
\hline Albuque rque & 72,840 & 273,150 & 291,360 & 364,200 & $1,383,960$ & $1,638,900$ \\
\hline San Diego & 67,280 & 252,300 & 269,120 & 336,400 & $1,278,320$ & $1,513,800$ \\
\hline Houston & 65,200 & 244,500 & 260,800 & 326,000 & $1,238,800$ & $1,467,000$ \\
\hline New Orleans & 57,220 & 271,195 & 500,675 & 286,100 & $1,087,180$ & $1,287,450$ \\
\hline
\end{tabular}


2. to sharply reduce casualties including sensibly conceived, protective construction systematically extended from the rural into the suburban and urban areas. There can be no doubt that such action could and would reduce casualties, depending on a variety of circumstances, from the very high tens of millions to the low millions in case of a nuclear war. In fact, such measures might well be a potent factor in preventing a nuclea $\mathrm{r}$ exchange. This is so simply because with survival the re could be retaliation, without survival the re would be none.

There are but few reasonably informed people who do or will challenge the last few statements made above. The problem is not "What makes sound sense?" This is known. Rather, the problem concerns social consciousness and what it takes to "sell" good sense in the face of the paralyzing inertia that today shackles the minds of men who do not "see" because they choose not to. The responsibility is everyone's - yours, ours, the cities', the states', the governments', civilians and military alike. The philosophy is as simple as that of the farmers of America's great plains who learned in their youth to build cyclone shelters - they might lose their houses, but would save their lives. In today's world of nuclear power, the citizenry should utilize protective construction - they might lose or keep the peace, lose or keep their cities, but in case of attack they and the nation might well survive.

Last and with equal simplicity, those who contemplate the physics and biology of blast effects and succeed in relating such information to modern, large-scale explosives, will know that prevention and prophylaxis comprise the course of sagacity. Too, those who have used vaccination along with epidemiologic and sanitary principles in support of sound clinical care to save the sick and gain long term control of communicable disease, understand the impact of knowledge and action contrasted with the futility of hoping a given epidemic would just disappear. Nuclear explosives are with us today and will not just disappear. The world after 1945, the year the first atomic explosion occurred in New Mexico, is not the same as it was before. Times have changed. So also must the habits of man. Even now "the future" is measuring the adaptability of people and societies the world over. For sure, only the most flexible will survive. 
1. D.R.Hooker, "Physiological Effects of Air Concussion," Am. J. Physiol., 67-68:219-274, 1923-24.

2. Hans Desaga, "Blast Injuries," Chap. XIV-D, pp. 1274-1293, German Aviation Medicine, World War II, Vol. II, U.S.Government Printing Office, Washington, 1950.

3. Theodor Benzinger, "Physiological Effects of Blast in Air and Water," Chap. XIV-B, pp. 1225-1259, German Aviation Medicine, World War II, Vol. II, U.S.Government Printing Office, Washington, 1950.

4. Robert Rõssle, "Pathology of Blast Effects," Chap. XIV-C, pp. 12601273, German Aviation Medicine, World War II, Vol. II, U.S.Government Printing Office, Washington, 1950.

5. H. Schardin, "The Physical Principles of the Effects of a Detonation," Chap. XIV-A, Pp. 1207-1244, German Aviation Medicine, World War II, Vol. II, U.S.Government Printing Office, Washington, 1950.

6. S. Zuckerman, "The Problem of Blast Injuries," Proc. Roy. Soc. Med., 34: $171-188,1941$.

7. Carl-Johan Clemedson, "An Experimental Study on Air Blast Injuries," Acta Physiol. Scand., 18, Suppl. 61, Uppsala, 1949.

8. V. Blocker and T. G. Blocker, "The Texas City Disaster - A Survey of 3,000. Casualties," Am. Jour. Surg., LXXVIII:756-771, 1949.

9. C. S. White, T. L. Chiffelle, D. R. Richmond, W. H. Lockyear, I. G. Bowen, V. C. Goldizen, H. W. Merideth, D. E. Kilgore, B. B. Longwell, J. T. Parker, F. Sherping, and M. E. Cribb, "Biological Effects of Pressure Phenomena Occurring Inside Protective Shelters Following a Nuclear Detonation, "Operation Teapot Report, WT-1179, October 28, 1957.

10. I. G. Bowen, A. F. Strehler, and M. B. Wetherbe, "Distribution and Density of Missiles from Nuclear Explosions," Operation Teapot Report, WT-1168, December 14, 1956.

11. I. G. Bowen, D. R. Richmond, M. B. Wetherbe, and C. S. White, "Biological Effects of Blast from Bombs. Glass Fragments as Penetrating Missiles and Some of the Biological Implications of Glass Fragmented by Atomic Explosions, " Lovelace Foundation for Medical Education and Research Report, AECU-3350, June 18, 1956. 
12. Benedict Cassen, Katherine Kistler, and Wanda Mankiewicz, "Lung Hemorrhage Produced in Heparinized Mice by Air Blast," J. Aviat. Med., 23:115-119, 1952.

13. C. S. White, "Blast Biology - A Summary," a contribution to the Holifield Subcommittee Hearings, May 1, 1958. Published in Report of Hearings before a Subcommittee of the Committee on Government Operations, House of Representatives, Part I- Atomic Shelter Tests, pp. 80-93, U.S.Government Printing Office, Washington, 1958.

14. C. S. White, "Biological Blast Effects," presented before The Special Subcommittee on Radiation during Public Hearings on The Biological and Environmental Effects of Nuclear War, Washington, D. C., June 24, 1959.

15. C. S. White and I. G. Bowen, "Comparative Effects Data of Biological Interest," First Draft - corrected and expanded, AEC Project Report, April 10, 1959.

16. Carl-Johan Clemedson, "Blast Injury," Physiol. Revs., 36:336-354, 1956.

17. A. H. Shapiro, The Dynamics and Thermodynamics of Compressible Fluid Flow, Vol. II, Ronald Press Co., New York, 1954.

18. R. V. Taborelli, I. G. Bowen, and E. R. Fletcher, "Tertiary Effects of Blast - Displacement," Operation Plumbbob Report, WT-1469, May 22, 1959.

19. E. S. Gurdjian, J. E. Webster, and H. L. Lissner, "Studies on Skull Fracture with Particular Reference to Engineering Factors," Am. J. Surg., 78:736-742, 1949.

20. Hans Desaga, "Experimental Investigations of the Action of Dust," Chap. XIII-B, pp. 1188-1203, German Aviation Medicine, World War II, Vol. II, U. S. Government Printing Office, Washington, 1950.

21. C. S. White, M. B. Wetherbe, and V. C. Goldizen, "The Internal Envi ronment of Underground Structures Subjected to Nuclear Blast. I. The Occurrence of Dust," Operation Plumbbob Report, ITR-1447, November 22, 1957.

22. Robert H. Cole, "Underwater Explosions," Princeton University Press, Princeton, N.J., 1948. 
23. Car1-Johan Clemedson, L. Deffet, R. Rucquoi Fornaeus, and P. Van de Wouwer, "Highspeed Radiographic Visualization of a Highexplosive Shock Wave in Muscular Tissue," J. Appl. Physiol., 7:604-608, May 1955.

24. Albert R. Behnke, "Decompression Sickness Following Exposure to High Pressures," Chap. III, pp.53-89, in Decompression Sickness, edited by John F. Fulton, W. B. Saunders Co., Philadelphia, 1951.

25. E. Newton Harvey, "The Mechanism of Wounding by High-velocity Missiles," Proc. Am. Phil. Soc., 92:294-304, 1948.

26. A. B. DuBois, A. W. Brody, D. H. Lewis, and B. F. Burgess, "Response of Chest Wall, Abdomen, and Diaphragm to Forced Oscillations of Volume," Fed. Proc., 13:38, 1954.

27. James Roman, "Effects of Severe Whole Body Vibration on Mice and Methods of Protection from Vibration Injury," WADC Technical Report 58-107. Aero Medical Laboratory, Wright Air Development Center, Air Research and Development Command, Wright-Patterson Air Force Base, Ohio, April 1958.

28. F. W. Brown III and R. H. Lee, "Injury from the Decompression Component of an Air-blast Wave," Nature, 178:490, 1956.

29. R. B. Fisher, P. L. Krohn, and S. Zuckerman, "The Relationship Between Body Size and the Lethal Effects of Blast," Ministry of Home Security Report R.D.284, Oxford University, Oxford, England, dated 10.12. 41 .

30. R. B. Fisher, P. L. Krohn, and S. Zuckerman, "The Relationship Between Body Size and the Lethal Effects of Blast," Ministry of Home Security Report B.P.C. 146/W.S.11, Oxford University, Oxford, England, dated 23.11.41.

31. Hjördis Celander, Carl-Johan Clemedson, U1f A. Ericsson, and H. Hultman, "A Study of the Relation Between the Duration of a Shock Wave and the Severity of the Blast Injury Produced by It," Acta Physiol. Scand. , 33:14-18, 1955.

32. D. R. Richmond, R. V. Taborelli, F. Sherping, M. B. Wetherbe, R. T. Sanchez, V. C. Goldizen, and C. S. White, "Shock Tube Studies of the Effects of Sharp-rising, Long-duration Overpressures on Biological Systems," Proceedings of Third Shock Tube Symposium, 
sponsored by the Air Force Special Weapons Center, Report SWR-TM59-2, March 10-12, 1959.

33. H. Schardin and $O$. Wünsche, "Versuche an Kleintieren zur Bestimmung der Druckstasstődlichkeitsgrenze," Bericht V 17, Deutsche Versuchsanstalt für Luftfahrt e.V., January 1958.

34. Carl-Johan Clemedson and H. Pettersson, "Propagation of High Explosive Shock Waves Through Different Parts of an Animal's Body, "Am. J. Physiol., 184:119-126, 1956.

35. D. R. Richmond, M. B. Wetherbe, R. V. Taborelli, T. L. Chiffelle, and C. S. White, "The Biologic Response to Overpressure. I. Effects on Dogs of Five to Ten-second Duration Overpressures Having Various Times of Pressure Rise," J. Aviat. Med., 28:447-460, 1957.

36. S. Zuckerman, "Experimental Study of Blast Injuries to the Lungs," Lancet, II:219-238, August 24, 1940.

37. G.R. Osborn, "Phrenico-Costal Sinus Pneumonia," Brit. Med. J., 2:317-318, 1940 .

38. G. R. Osborn, "Pulmonary Concussion ('Blast')," Brit. Med. J., $1: 506-510,1941$.

39. Külbs, "Lunge und Trauma," Arch. f. exper. Path. u. Pharmakol. $62: 39-46,1909$.

40. R. A. Danie1, Jr., "Bullet Wounds of Lungs; Experimental Study," Surg., 15:774-782, 1944.

41. E. Newton Harvey, I. M. Korr, G. Oster, and J.H. McMillen, "Secondary Damage in Wounding Due to Pressure Changes Accompanying the Passage of High-velocity Missiles," Surg., 21:218-239, 1947.

42. AEC Project, Lovelace Foundation for Medical Education and Research, Albuque rque, New Mexico, unpublished data.

43. J. A. Armstrong, D. I. Fryer, W. K. Stewart, and H. E. Whittingham, "Interpretation of Injuries in the Comet Aircraft Disasters - An Experimental Approach," Lancet I:1135-1143, 1955.

44. D. R. Richmond, R. V. Taborelli, I. G. Bowen, T. L. Chiffèlle, F. G. Hirsch, B. B. Longwell, J. G. Riley, C. S. White, F. Sherping, V. C. Goldizen, J. D. Ward, M. B. Wetherbe, V. R. Clare, M. L. 
Kuhn, and R. T. Sanchez, "Blast Biology - A Study of the Primary and Tertiary Effects of Blast in Open Underground Protective Shelters, " Operation Plumbbob Report, WT-1467, June 30, 1959.

45. P. L. Krohn, D. Whitteridge, and S. Zuckerman, "Physiological Effects of Blast," Lancet I:252-258, Feb. 28, 1942.

46. T. Benzinger, "Causes of Death from Blast," Am. J. Physiol., 167:767, 1951.

47. Carl-Johan Clemedson and H. Hultman, "Air Embolism and the Cause of Death in Blast Injury," Military Surgeon, 114:424-437, 1954.

48. F. J. Gouze and R. Hayter, "Air Embolism in Immersion Blast," U.S. Naval Med. Bulletin, 43:871-877, 1944.

49. C. M. Van Allen, L. S. Hrdina, and J. Clark, "Air Embolism from the Pulmonary Vein - A Clinical and Experimental Study, "Arch. Surg., 19:567-599, 1929.

50. T. M. Durant, M. J. Oppenheimer, M. R. Webster, and Joan Long, "Arterial Air Embolism," Am. Heart J. , 38:481-500, 1949.

51. W. H. Chase, "Anatomical and Experimental Observations in Air Embolism," Surg. Gyn. \& Obst., LIX:569-577, 1934.

52. C. -J. Clemedson and H. Pettersson, "Genesis of Respiratory and Circulatory Changes in Blast Injury," Am. J. Physiol., 174:316$320,1953$.

53. B. S. Leavell, "Acute Heart Failure Following 'Blast Injury'," War Med., 7:162-167, 1945.

54. D. W. Barrow and H. T. Rhoads, "Blast Concussion Injury," J.A. M.A., 125:900-902, 1944.

55. Benedict Cassen, Katherine Kistler, and Wanda Mankiewicz, "Some Effects of Air Blast on Mechanically Constrained Mice," J. Aviat. Med., 23:120-129, 1952.

56. Wharton M. Young, "Mechanics of Blast Injury," War Med., 8:7381,1945 .

57. J. M. Miller, "Rupture of the Heart from Blast Injury," Arch. Path. 13:406-407, 1947 .

58. V. C. Goldizen, Unpublished data, AEC Project, Lovelace Foundation for Medical Education and Research, Albuquerque, N. M. 
59. J. D. King and G. M. Curtis, War Medicine-A Symposium: Lung Injury Due to the Detonation of High Explosives, edited by W. S. Pugh, New York Philosophical Library, 1942.

60. G. Hadfield, "Problems of Blast Injuries," Lancet I:110-111, 1941.

61. C. A. Birch, "Air Embolism," The Fractitioner, 165:164-170, 1950.

62. J. Fine and J. Fischmann, "An Experimental Study of the Treatment of Air Embolism," N.Eng. J.Med., 223:1054-1057, 1940.

63. Carol H. Kretzschmar, "Wounds of the Chest Treated by Artificial Pneumothorax," Lancet I:832-834, 1940.

64. D. M. Dean, A. R. Thomas, and R. S. Allison, "Effects of High Explosive Blast on the Lungs," Lancet II:224-226, 1940.

65. G. Hadfield, "A Case of Fulmonary Concussion ('Blast') Due to High Explosive," Brit. Med. J., I:77-78, 1941.

66. J. V. Wilson and R. E. Tunbridge, "Pathological Findings in a Series of Blast Injuries," Lancet I:257-261, 1943.

67. J. N. O'Reilly, "Blast Injury of the Lungs," Lancet II:423-428, 1941.

68. J.E.H.Roberts, "Chest Surgery," Lancet II, 781, 1940.

69. J.E.H.Roberts, "Blast Injuries," Brit. Med. J., 2:843, 1940.

70. H. J. Schattenberg and J. Ziskind, "Air Embolism as a Complication of Artificial Pneumothorax," Am. J. Clin. Path., 9:477-482, 1939.

71. P. H. Dagelish, "Two Cases of Air Embolism," Brit. Med. J., 2 256, 1945.

72. R. T. Wong, "Air Emboli in Retinal Arteries. Report of a Case," Arch. Ophth., 25:149-150, 1941.

73. G. W. Reyer and H. W. Kohl, "Air Embolism Complicating Thoracic Surgery," J.A.M.A., 87:1626-1630, 1926.

74. E. Wever, "Cerebrale Luftembolie," Beitr.z. Klin.d. Tuberk., $31: 159-230,1914$.

75. G. Liebermeister, "Anamisches Zungenphanomen, ein Fruhsymptom der Arteriellen Luftembolie," Klin Wchnschr., 8:21-23, 1929.

76. W. S. Pugh, War Medicine, Editor, New York Philosophical Library, 1942.

77. A. Ruskin, O. W. Beard and R. L. Schaeffer, "Blast Hypertension Elevated Arterial Pressures in the Victims of the Texas City Disaster," Am. J. Med., IV:228-236, 1948. 
78. A. Ruskin and O. W. Beard, "The Texas City Disaster-Cardiovascular Studies, with Follow-up Results," Texas Reports on Biolog. and Med., 6:243-259, 1948.

79. Samuel Glasstone, The Effects of Nuclear Weapons, editor, Armed Forces Special Weapons Project, Department of Defense, U.S.Government Printing Office, Washington, D.C., June 1957.

80. Samuel Glasstone, Executive Editor, The Effects of Atomic Weapons, prepared for and in cooperation with the U.S. Department of Defense and the U.S. Atomic Energy Commission under the direction of the Los Alamos Scientific Laboratory, U.S. Government Printing Office, Washington, D.C., June 1950.

81. Teofil Zalewski, "Experimentelle Untersuchungen über die Resistenzfähigkeit des Trommelfells," Z. Ohrenheilk, 52:109-128, 1906.

82. S. Zuckerman, "Rupture of the Ear Drums by Blast," Ministry of Home Security Report B.P.C. 148/W.S.13, University of Oxford, Oxford, England, Nov. 22, 1941.

83. P. M. Blake, J.W.B. Douglas, P. L. Krohn, and S. Zuckerman, "Rupture of the Ear-drums by Blast," Military Personnel Research Committee (Medical Research Council), Report B.P.C. 43/179/W.S. 21, Oxford University, Oxford, England, undated.

84. A. N. Black, D. G. Christopherson, and S. Zuckerman, "Fractures of the Head and Feet," Ministry of Home Security, Report R.C.334, Oxford University, Oxford, England, August 12, 1942.

85. S. Zuckerman, "The Effects of Direct Concussion on Monkeys in Underground Shelters," Ministry of Home Security, Report R.C. 65, Oxford University, Oxford, England, December 1939.

86. S. Zuckerman and A. N. Black, "The Effect of Impacts on the Head and Back of Monkeys," Ministry of Home Security, Report R. C. 124, Oxford University, Oxford, England, August 26, 1940.

87. R. H. Draeger, J. S. Barr, J. Y. Dunbar, W. W. Sager, and M. C. Shelesnyak, "A Study of Personnel Injury by 'Solid Blast' and the Design and Evaluation of Protective Devices, " Nava1 Medical Research Institute Report No. 1, Project X-5.17, Bethesda, Md., March 30, 1945. 
88. I. G. Bowen, "Missiles Secondary to Nuclear Blast," Report on Project 33.2, Operation Plumbbob Report, WT-1468, Lovelace Foundation for Medical Education and Research, Albuquerque, New Mexico - in preparation.

89. Don Golenpaul, Edito', Information Please Almanac, pp. 408-411 (quoting data from U. S. Bureau of the Census), The MacMillan Company, New York City, 1959. 